\title{
INTERMEDIATION REDUCES PUNISHMENT (AND REWARD) WEB APPENDIX
}

\author{
Lucas C. Coffman*
}

April 13, 2011

\section{Contents}

1. Order Effects and Within-Subject Consistency, p. 1

2. Do Subjects Not Account for the Intermediary's Endowment?, p.2

3. Who's-the-Dictator? Game, p. 2

4. Charity Experiment framing, p. 3

5. Trolley Scenario, p. 4

6. Extra Tables, p. 5

7. Additional References, p. 15

8. Experiment Instructions, Slideshows and Scripts, p. 16 


\section{Order Effects and Within-Subject Consistency}

The subjects played the game for four periods, in all four roles. This begs two questions. First, does the order of roles played affected decisions as a punisher? Second, do subjects show behavioral correlations across roles? We find no evidence of order effects with respect to the main result, but we do find within-subject correlations.

Role order does not affect how subjects punished indirectness. Table 5 includes three dummy variables (Played as A, B or C) which equal 1 if at the time the subject was a punisher, she had already played the game in the role specified 1 . The triple interactions in this specification show that how much punishment decreases when the game is sold is not affected by these order effects. The coefficients of the three-way interactions in the table (Profit over $\$ 5 *$ Sold * Punisher played as Role -- before) identify how much punishment decreases when the DG is sold for punishers who played the game in each of the other roles first. None of these coefficients are statistically different than zero indicating that the punishment decrease is not impacted by the order of roles the subject experienced. Another way to read the table is that in Period 1, when the punisher is untainted by experience, there is still a significant decrease in punishment for money made indirectly. This is evidenced in the statistically significant coefficient of the interaction of first mover's profit and whether she sold the DG.

Table 6 shows evidence of some behavioral consistency across roles. This table runs OLS regressions interacting the two main drivers of punishment - 'Player A's profit above \$5' and 'Player A's profit when the game was sold' - with (i) whether the punisher sold the DG when she was player A and separately with (ii) how much profit above $\$ 5$ she claimed for herself as Player A. Model I includes the data from all players. The first three rows show, respectively, punishment increases as Player A's profit increases, this is not different for punishers who sold the DG, but it is less for punishers who claimed (or will claim) more money when they were Player A. That is, they do not punishing selfishness as harshly if they were (or are going to be) selfish themselves. The next three rows, respectively, show that punishment of profit made decreases if made by selling (Result 1 in the paper), this decrease is much greater for punishers who sold the game themselves, and it is no different for punishers who made (or will make) a lot of money as Player A. In other words, subjects who take (or will take) the indirect action, punish indirectness less harshly.

\footnotetext{
${ }^{1}$ Subjects all played the game in the order $D \rightarrow C \rightarrow B \rightarrow A \rightarrow D$. Thus we do not have any data for subjects who only played as $\mathrm{C}$ or B before they punished; they always played as A as well.
} 


\section{Do Subjects Not Account for the Intermediary's Endowment?}

There is reasonable concern that the punishers do not account for the intermediary's $\$ 5$ endowment when making their fairness judgments. If the punisher thinks both the intermediary and the receiver have $\$ 0$, then "selling" the DG can be construed as a pro-social move, granting a poor player a chance to receive some wealth. This would drive similar punishment patterns as we observe. Thus let us consider only scenarios where the first mover does not leave enough for money to be shared amongst the other two players. If the first mover chooses to make $\$ 9$ or $\$ 10$, then there is $\$ 1$ or $\$ 0$ left over. Since dollars are indivisible in this game, selling the game for $\$ 9$ or keeping $\$ 9$ in the DG should be identical: The first mover has chosen a final allocation of $(\$ 9, \$ 1, \$ 0)$ or $(\$ 9, \$ 0, \$ 1)$. To keep the outcome constant, let us only consider scenarios where the intermediary passes the dollar to the receiver, so the final allocation is $(\$ 9, \$ 0, \$ 1)$. We shall also restrict the analysis to punishers who do not (mistakenly) shift any blame to the intermediary in any of these scenarios. That is, we only include punishers who do not punish the intermediary in the four scenarios we have isolated - Sell for $\$ 10$, Don`t Sell and Keep $\$ 10$, Sell for $\$ 9$ and intermediary passes the $\$ 1$, and Don`t Sell and Keep $\$ 9$.

Restricting our analysis thusly does not change the punishment comparisons. A two-tailed, signed rank test rejects the hypothesis that the punishments are the same whether the first mover sells or not with a $\mathrm{p}=0.02$. Similarly, a Fisher Pitman matched pair permutation test rejects the same hypothesis at the same level $(\mathrm{p}=0.02)$.

\section{The Who's-the-Dictator Game - Design}

This game is a reframing of The Intermediation Game (and hence also The Allow-Taking Game) designed to test two potential explanations why intermediation may reduce punishment in The Intermediation Game. First is the hypothesis that selling the DG to the intermediary is less reprehensible because it is framed as a market transaction (since the term "sell" is used). Second is the hypothesis that The Allow-Taking Game finds no difference in punishment because the act of taking is more outrageous than keeping, and changing this frame may change the punishment imposed. In this game, the first mover first decides who starts with the $\$ 10$, herself or the receiver. If she starts with the $\$ 10$, then she plays a $\$ 10$ DG with the receiver. If the receiver starts with the $\$ 10$, then the intermediary decides how much of the $\$ 10$ to take. First though, the first mover also decides how much the intermediary must take and pass to her. The intermediary must take at least this much from the receiver's $\$ 10$. Anything she takes on top of this amount is the intermediary's 
profit for the game. After either process, the punisher can reduce the first mover's payout. The punishment technology and elicitation is identical to those in The Intermediation Game.

One session of 24 subjects was run in October, 2009 at the Computer Lab for Experimental Research at Harvard Business School. The session last for one hour.

\section{The Who's-the-Dictator Game - Results}

The data are fewer and noisier than those provided by The Intermediation Game, but there is evidence that intermediation reduces punishment. As in The Intermediation Game, this holds when misbehavior, and punishment, is high. Table 4 shows that when the first mover makes $\$ 10$, she is punished less when the intermediary passes her the money than if she took it herself. The results for $\$ 9$ are slightly mixed: The p-value from a matched pair signed rank test is 0.2 while the p-value from a Fisher-Pitman permuatation test of the data is 0.07. This indicates that, if there is an effect, it may be driven by few, large differences rather than many, small differences.

The effect intermediation has on punishment seems to be smaller, or at least noisier, in this game compared to The Intermediation Game. This could be due to, among other reasons, subject pool differences, different sample sizes, and one of the two hypotheses proposed in the design description of this game. Though speculative, framing the use of an intermediary as a market transaction, or switching from a giving frame to a taking frame, may reduce punishment as well.

\section{Charity Experiment Framing}

\section{First Person Donation Framing}

Direct Framing: We would like to offer an opportunity to do something great with a portion of your winnings. You can purchase a mosquito net for a pregnant mother in Busia, Kenya (via TamTam Africa, www.tamtamafrica.org). We will match you dollar for dollar in purchasing nets. So even though they usually cost $\$ 7$, for $\$ 3.50$ you can purchase 1 net, for $\$ 7$, two nets, etc. Since you have won $\$ 70$, you may purchase anywhere between 0 and 20 nets to be given to pregnant women in Kenya (via TamTam Africa).

Indirect Framing: We would like to offer an opportunity to do something great with a portion of your winnings. You can donate money to a charity, TamTam Africa (www.tamtamafrica.org), enabling them to buy mosquito nets for pregnant mothers in Busia, Kenya. We will match you dollar for dollar in your donation. So even though it 
usually takes a donation of $\$ 7$ for TamTam to be able to purchase a net, for a donation of $\$ 3.50$ from you, then can purchase 1 net, for $\$ 7$, two nets, etc. Since you have won $\$ 70$, you may make a donation that helps them purchase anywhere between 0 and 20 nets to be given to pregnant women in Kenya.

\section{Trolley Scenario}

The workhorse of the Moral Psychology literature has long been the "trolley problem". This was originally a thought experiment constructed by Philippa Foot (1978), but has since been widely used in lab experiments. A script of the trolley scenario usually reads something like this:

Suppose a runaway trolley is about to run over and kill five people. Suppose further that you can hit a switch that will divert the trolley onto a different set of tracks where it will kill only one person instead of five. Is it okay to hit the switch? Now, what if the only way to save the five people were to push a large person (larger than yourself) in front of the trolley, killing him but saving the others? Would that be okay? (Green \& Haidt 2002)

Study participants typically say that pulling the lever is okay but pushing the large person is not. Less the size of one man, the tradeoffs are identical, but in the eyes of a moral judge, the two situations are quite different. 


\section{Tables}

Table 1: Average Punishment for Each Scenario

\begin{tabular}{|c|c|c|c|c|}
\hline Scenario & Sold? & Price & Amt. Kept & Avg. Punishment \\
\hline \multirow[t]{2}{*}{1} & No & - & $\$ 5$ & 0.69 \\
\hline & & & & $(0.21)$ \\
\hline \multirow[t]{2}{*}{2} & No & - & $\$ 6$ & 1.30 \\
\hline & & & & $(0.25)$ \\
\hline \multirow[t]{2}{*}{3} & No & - & $\$ 7$ & 2.03 \\
\hline & & & & $(0.28)$ \\
\hline \multirow[t]{2}{*}{4} & No & - & $\$ 8$ & 2.89 \\
\hline & & & & $(0.33)$ \\
\hline \multirow[t]{2}{*}{5} & No & - & $\$ 9$ & 4.00 \\
\hline & & & & $(0.39)$ \\
\hline \multirow[t]{2}{*}{6} & No & - & $\$ 10$ & 5.22 \\
\hline & & & & $(0.48)$ \\
\hline \multirow[t]{2}{*}{7} & Yes & $\$ 5$ & $\$ 5$ & 0.78 \\
\hline & & & & $(0.22)$ \\
\hline \multirow[t]{2}{*}{8} & Yes & $\$ 5$ & $\$ 6$ & 0.89 \\
\hline & & & & $(0.22)$ \\
\hline \multirow[t]{2}{*}{9} & Yes & $\$ 5$ & $\$ 7$ & 1.06 \\
\hline & & & & $(0.24)$ \\
\hline \multirow[t]{2}{*}{10} & Yes & $\$ 5$ & $\$ 8$ & 1.03 \\
\hline & & & & $(0.23)$ \\
\hline \multirow[t]{2}{*}{11} & Yes & $\$ 5$ & $\$ 9$ & 1.03 \\
\hline & & & & $(0.23)$ \\
\hline \multirow[t]{2}{*}{12} & Yes & $\$ 5$ & $\$ 10$ & 1.27 \\
\hline & & & & $(0.26)$ \\
\hline \multirow[t]{2}{*}{13} & Yes & $\$ 6$ & $\$ 6$ & 1.19 \\
\hline & & & & $(0.26)$ \\
\hline \multirow[t]{2}{*}{14} & Yes & $\$ 6$ & $\$ 7$ & 1.36 \\
\hline & & & & $(0.26)$ \\
\hline \multirow[t]{2}{*}{15} & Yes & $\$ 6$ & $\$ 8$ & 1.45 \\
\hline & & & & $(0.27)$ \\
\hline \multirow[t]{2}{*}{16} & Yes & $\$ 6$ & $\$ 9$ & 1.59 \\
\hline & & & & $(0.29)$ \\
\hline 17 & Yes & $\$ 6$ & $\$ 10$ & 1.44 \\
\hline \multicolumn{5}{|c|}{ Continued on next page } \\
\hline
\end{tabular}


Table 1 - continued from previous page

\begin{tabular}{|c|c|c|c|c|}
\hline Scenario & Sold? & Price & Amt. Kept & $\begin{array}{c}\text { Avg. Punishment } \\
(0.28)\end{array}$ \\
\hline \multirow[t]{2}{*}{18} & Yes & $\$ 7$ & $\$ 7$ & 2.02 \\
\hline & & & & $(0.33)$ \\
\hline \multirow[t]{2}{*}{19} & Yes & $\$ 7$ & $\$ 8$ & 2.05 \\
\hline & & & & $(0.31)$ \\
\hline \multirow[t]{2}{*}{20} & Yes & $\$ 7$ & $\$ 9$ & 1.94 \\
\hline & & & & $(0.32)$ \\
\hline \multirow[t]{2}{*}{21} & Yes & $\$ 7$ & $\$ 10$ & 1.91 \\
\hline & & & & $(0.32)$ \\
\hline \multirow[t]{2}{*}{22} & Yes & $\$ 8$ & $\$ 8$ & 2.50 \\
\hline & & & & $(0.35)$ \\
\hline \multirow[t]{2}{*}{23} & Yes & $\$ 8$ & $\$ 9$ & 2.38 \\
\hline & & & & $(0.36)$ \\
\hline \multirow[t]{2}{*}{24} & Yes & $\$ 8$ & $\$ 10$ & 2.56 \\
\hline & & & & $(0.36)$ \\
\hline \multirow[t]{2}{*}{25} & Yes & $\$ 9$ & $\$ 9$ & 3.59 \\
\hline & & & & $(0.43)$ \\
\hline \multirow[t]{2}{*}{26} & Yes & $\$ 9$ & $\$ 10$ & 3.45 \\
\hline & & & & $(0.42)$ \\
\hline 27 & Yes & $\$ 10$ & $\$ 10$ & 4.30 \\
\hline \multicolumn{5}{|c|}{ Standard errors reported, clustered at subject level } \\
\hline \multicolumn{5}{|c|}{ Every average punishment statistically greater than zero, with $\mathrm{p}<0.01$} \\
\hline
\end{tabular}


Table 2: OLS Regressions: Reflection Treatment

\begin{tabular}{lcc}
\hline \hline \multicolumn{3}{c}{ Dep. Var. $=$ Punishment (\$) } \\
\hline \hline & All Subjects & 15 "Wise" Subjects \\
& $(\mathrm{I})$ & $(\mathrm{II})$ \\
\hline First Mover's Profit $(\$)$ & $1.14^{* * *}$ & $1.09^{* * *}$ \\
over $\$ 5$ & $(0.16)$ & $(0.21)$ \\
First Mover's Profit & $-0.33^{* * *}$ & $-0.41^{* * *}$ \\
over $\$ 5 *$ Sold & $(0.10)$ & $(0.12)$ \\
Intermediary's Profit & $0.09^{* * *}$ & 0.04 \\
& $(0.03)$ & $(0.03)$ \\
Sold Dummy & 0.10 & $0.39^{*}$ \\
& $(0.29)$ & $(0.20)$ \\
Period & -0.42 & -0.29 \\
& $(0.31)$ & $(0.38)$ \\
Constant & 1.31 & 1.25 \\
& $(0.97)$ & $(1.31)$ \\
\hline Standard Errors Clustered at Subject Level & \\
$* * *, * *, *$ indicates $\mathrm{p}<0.01,0.05,0.1$ respectively \\
\hline
\end{tabular}

Table 3: The Taking Game: Using a Third Party Does Not Reduce Punishment ${ }^{a}$

\begin{tabular}{|c|c|c|c|c|c|c|}
\hline & \multicolumn{2}{|c|}{ Avg. Punishment } & \multicolumn{2}{|c|}{ No. Subjects Who Punish } & \multicolumn{2}{|c|}{$\overline{p \text {-values }}$} \\
\hline $\begin{array}{r}\text { Profit of } \\
\text { First Mover }\end{array}$ & $\begin{array}{c}\text { Taking } \\
\text { Not Allowed }\end{array}$ & $\begin{array}{l}\text { Taking } \\
\text { Allowed }\end{array}$ & $\begin{array}{l}\text { Not Allowing } \\
\text { Taking More }\end{array}$ & $\begin{array}{c}\text { Allow Taking } \\
\text { More }\end{array}$ & $\begin{array}{l}\text { Matched Pair, } \\
\text { Signed Rank }\end{array}$ & $\begin{array}{c}\text { Permutation } \\
\text { Test }^{c}\end{array}$ \\
\hline$\$ 10$ & $\$ 4.08$ & $\$ 3.67$ & $\overline{4}$ & $\overline{3}$ & 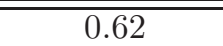 & $\overline{0.40}$ \\
\hline$\$ 9$ & $\$ 2.83$ & $\$ 3.04$ & 3 & 5 & 0.43 & 0.44 \\
\hline$\$ 8$ & $\$ 2.17$ & $\$ 2.35$ & 2 & 6 & 0.18 & 0.60 \\
\hline$\$ 7$ & $\$ 2.13$ & $\$ 1.63$ & 5 & 3 & 0.42 & 0.31 \\
\hline$\$ 6$ & $\$ 1.33$ & $\$ 1.21$ & 4 & 6 & 0.72 & 0.87 \\
\hline$\$ 5$ & $\$ 0.50$ & $\$ 0.79$ & 0 & 4 & 0.05 & 0.12 \\
\hline
\end{tabular}

\footnotetext{
${ }^{a}$ To hold outcomes constant, only scenarios where intermediary makes no money included

${ }^{b}$ Matched Pair Signed Rank test based on null hypothesis that punishment distributions are identical for including and not including intermediary. Pairs matched by subject.

${ }^{c}$ Permutation p-values based on 200,000 simulations per test. P-values do not change at the hundredths level when re-run. Pairs matched by subject. P-values are from two-tailed tests.
} 
Table 4: Directness is Punished More Harshly in the Forced-Taking Game ${ }^{a}$

\begin{tabular}{r|cc|cc|c|c}
\hline \hline & \multicolumn{2}{|c|}{ Avg. Punishment } & \multicolumn{2}{|c|}{ No. Subjects } & Who Punish & \multicolumn{2}{|c}{ p-values } \\
$\begin{array}{r}\text { Profit of } \\
\text { First Mover }\end{array}$ & $\begin{array}{c}\text { DG } \\
\text { Unsold }\end{array}$ & $\begin{array}{c}\text { DG } \\
\text { Sold }\end{array}$ & $\begin{array}{c}\text { Unsold } \\
\text { More }\end{array}$ & $\begin{array}{c}\text { Sold } \\
\text { More }\end{array}$ & $\begin{array}{c}\text { Matched Pair, } \\
\text { Signed Rank }^{b}\end{array}$ & $\begin{array}{c}\text { Permutation } \\
\text { Test }^{c}\end{array}$ \\
\hline \hline$\$ 10$ & $\$ 7.67$ & $\$ 6.38$ & 6 & 1 & 0.05 & 0.03 \\
$\$ 9$ & $\$ 6.63$ & $\$ 5.58$ & 7 & 4 & 0.20 & 0.07 \\
$\$ 7$ & $\$ 4.13$ & $\$ 4.17$ & 5 & 5 & 0.66 & 1.00 \\
$\$ 6$ & $\$ 3.08$ & $\$ 3.13$ & 5 & 7 & 0.83 & 1.00 \\
$\$ 5$ & $\$ 1.92$ & $\$ 2.00$ & 5 & 3 & 0.31 & 0.89 \\
\hline \hline
\end{tabular}

${ }^{a}$ To hold outcomes constant, only scenarios where intermediary makes no money included

${ }^{b}$ Matched Pair Signed Rank test based on null hypothesis that punishment distributions are identical for direct and indirect action. Pairs matched by subject.

${ }^{c}$ Permutation p-values based on 200,000 simulations per test. P-values do not change at the hundredths level when re-run. Pairs matched by subject. P-values are from two-tailed tests. 
Table 5: OLS Regressions: Order Effects

\begin{tabular}{lc}
\hline \hline \multicolumn{1}{c}{ Dep. Var. = Punishment $(\$)$} \\
\hline \hline $\begin{array}{l}\text { First Mover's Profit (\$) } \\
\text { over } \$ 5\end{array}$ & $0.90^{* * *}$ \\
\hline First Mover's Profit & $-0.21^{* * *}$ \\
over $\$ 5{ }^{*}$ Sold & $(0.03)$ \\
\hline First Mover's Profit & -0.07 \\
over $\$ 5 *$ Sold & $(0.16)$ \\
$*$ Played as A first & \\
\hline First Mover's Profit & 0.01 \\
over $\$ 5$ Sold & $(0.17)$ \\
$*$ Played as B first & 0.00 \\
\hline First Mover's Profit & $(0.14)$ \\
over $\$ 5 *$ Sold & \\
$*$ Played as C first & $0.05^{* *}$ \\
\hline Intermediary's Profit & $(0.02)$ \\
\hline Sold Dummy & $0.31^{* * *}$ \\
& $(0.08)$ \\
\hline Played as A first & -0.77 \\
& $(0.72)$ \\
\hline Played as B first & -0.04 \\
& $(0.57)$ \\
\hline Played as C first & -0.02 \\
& $(0.56)$ \\
\hline Constant & $1.73^{* *}$ \\
\hline Session F.E. & $(0.77)$ \\
\hline$* * * *$ included \\
\hline Standard Errors Clustered at Subject Level \\
\end{tabular}


Table 6: OLS Regressions: Behavioral Consistency

\begin{tabular}{|c|c|c|c|}
\hline \multicolumn{4}{|c|}{ Dep. Var. = Punishment (\$) } \\
\hline & $\begin{array}{l}\text { All } \\
(\mathrm{I})\end{array}$ & $\begin{array}{l}\text { Sold as A } \\
\text { (II) }\end{array}$ & $\begin{array}{c}\text { Didn`t Sell as A } \\
\text { (III) }\end{array}$ \\
\hline $\begin{array}{l}\text { First Mover's Profit }(\$) \\
\text { over } \$ 5\end{array}$ & $\begin{array}{c}1.62^{* * *} \\
(0.38)\end{array}$ & $\begin{array}{l}1.71^{* *} \\
(0.67)\end{array}$ & $\begin{array}{c}1.64^{* * *} \\
(0.49)\end{array}$ \\
\hline $\begin{array}{l}\text { First Mover's Profit } \\
\text { over } \$ 5 \\
* \text { Sold DG as Player A }\end{array}$ & $\begin{array}{c}0.05 \\
(0.18)\end{array}$ & - & - \\
\hline $\begin{array}{l}\text { First Mover's Profit } \\
\text { over } \$ 5 \\
\text { *Profit made as A }\end{array}$ & $\begin{array}{l}-0.10^{*} \\
(0.05)\end{array}$ & $\begin{array}{l}-0.11 \\
(0.08)\end{array}$ & $\begin{array}{l}-0.09 \\
(0.07)\end{array}$ \\
\hline $\begin{array}{l}\text { First Mover's Profit } \\
\text { over } \$ 5 * \text { Sold }\end{array}$ & $\begin{array}{l}-0.39^{*} \\
(0.23)\end{array}$ & $\begin{array}{l}-0.57 \\
(0.53)\end{array}$ & $\begin{array}{l}-0.42^{*} \\
(0.24)\end{array}$ \\
\hline $\begin{array}{l}\text { First Mover's Profit } \\
\text { over } \$ 5 * \text { Sold } \\
\text { * Sold DG as Player A }\end{array}$ & $\begin{array}{c}-0.16^{*} \\
(0.09)\end{array}$ & - & - \\
\hline $\begin{array}{l}\text { First Mover's Profit } \\
\text { over } \$ 5 \text { *Sold } \\
\text { *Profit made as A }\end{array}$ & $\begin{array}{c}0.03 \\
(0.03)\end{array}$ & $\begin{array}{c}0.04 \\
(0.07)\end{array}$ & $\begin{array}{c}0.02 \\
(0.03)\end{array}$ \\
\hline Intermediary's Profit & $\begin{array}{l}0.05^{* *} \\
(0.02)\end{array}$ & $\begin{array}{l}0.04^{* *} \\
(0.02)\end{array}$ & $\begin{array}{c}0.07 \\
(0.05) \\
\end{array}$ \\
\hline Sold Dummy & $\begin{array}{c}0.31^{* * *} \\
(0.08)\end{array}$ & $\begin{array}{c}0.15^{* * *} \\
(0.06)\end{array}$ & $\begin{array}{c}0.48^{* * *} \\
(0.14)\end{array}$ \\
\hline Sold DG as Player A & $\begin{array}{l}-1.06 \\
(0.49)\end{array}$ & - & - \\
\hline Profit made as $\mathrm{A}$ & $\begin{array}{c}0.37^{* *} \\
(0.15) \\
\end{array}$ & $\begin{array}{l}0.41^{*} \\
(0.23) \\
\end{array}$ & $\begin{array}{c}0.29 \\
(0.22) \\
\end{array}$ \\
\hline Period & $\begin{array}{l}-0.20 \\
(0.25)\end{array}$ & $\begin{array}{l}-0.06 \\
(0.31)\end{array}$ & $\begin{array}{l}-0.30 \\
(0.38)\end{array}$ \\
\hline Constant & $\begin{array}{l}-0.88 \\
(1.46)\end{array}$ & $\begin{array}{c}0.13 \\
(3.31)\end{array}$ & $\begin{array}{l}-3.07 \\
(2.88)\end{array}$ \\
\hline Session F.E. & Included & Included & Included \\
\hline Observations & 64 & 33 & 31 \\
\hline
\end{tabular}

Table 7: What Punishment Amounts Were Common?

\begin{tabular}{lccc}
\hline \hline & All & Direct & Indirect \\
\hline No. Reported Punishments & 1,728 & 384 & 1,344 \\
\hline Punishment = $\$ 0$ & 884 & 157 & 727 \\
Punish Everything (to $\$ 0)$ & 253 & 57 & 196 \\
Equate w/ Punisher (to $\$ 5)$ & 188 & 64 & 124 \\
Equate w/ Receiver & 129 & 44 & 85 \\
Equate w/ Intermediary & 92 & NA & 92 \\
\hline When a punishment qualifies for more than one row, \\
it is only included in the first row for which it qualifies. \\
\hline \hline
\end{tabular}


Table 8: How Many Subjects Punish Directness More Harshly ${ }^{\dagger}$

\begin{tabular}{l|c}
\hline \hline \multicolumn{2}{c}{ No. Subjects Who... } \\
\hline $\begin{array}{l}\text { Punish Direct Action } \\
\text { Harsher More Frequently }\end{array}$ & 28 \\
\hline $\begin{array}{l}\text { Punish Direct Action } \\
\text { Harsher At Least Once }\end{array}$ & 36 \\
\hline $\begin{array}{l}\text { Never Punish Indirect Action } \\
\text { Harsher }\end{array}$ & 46 \\
\hline \hline Total No. Subjects & 64 \\
\hline \hline
\end{tabular}

Table 9: Is Directness Punished More Harshly? Controlling for Frequency ${ }^{a, b}$

\begin{tabular}{r|cc|cc|c|c}
\hline \hline & \multicolumn{2}{|c|}{ Avg. Punishment } & \multicolumn{2}{|c|}{ \# Subjects Who Punish } & \multicolumn{2}{c}{ p-values } \\
\hline $\begin{array}{r}\text { Profit of } \\
\text { First Mover }\end{array}$ & $\begin{array}{c}\text { DG } \\
\text { Unsold }\end{array}$ & $\begin{array}{c}\text { DG } \\
\text { Sold }\end{array}$ & $\begin{array}{l}\text { Unsold } \\
\text { More }\end{array}$ & $\begin{array}{c}\text { Sold } \\
\text { More }\end{array}$ & $\begin{array}{c}\text { Matched Pair, } \\
\text { Signed Rank }\end{array}$ & $\begin{array}{c}\text { Permutation } \\
\text { Test }^{d}\end{array}$ \\
\hline \hline$\$ 10$ & $\$ 7.20$ & $\$ 6.58$ & 16 & 4 & 0.01 & 0.07 \\
$\$ 9$ & $\$ 5.44$ & $\$ 5.35$ & 9 & 6 & 0.46 & 0.76 \\
$\$ 8$ & $\$ 4.21$ & $\$ 3.95$ & 11 & 7 & 0.30 & 0.30 \\
$\$ 7$ & $\$ 3.55$ & $\$ 4.10$ & 5 & 11 & 0.09 & 0.06 \\
$\$ 6$ & $\$ 3.22$ & $\$ 3.22$ & 5 & 5 & 1.00 & 1.00 \\
$\$ 5$ & $\$ 4.30$ & $\$ 4.30$ & 0 & 0 & 1.00 & 1.00 \\
\hline \hline
\end{tabular}

${ }^{a}$ To hold outcomes constant, only scenarios where intermediary makes no money included

${ }^{b}$ To test if punishment is affected by intermediation beyond the frequency of punishing, only matched pairs with two nonzero punishments are included.

${ }^{c}$ Matched Pair Signed Rank test based on null hypothesis that punishment distributions are identical for direct and indirect action. Pairs matched by subject.

${ }^{d}$ Permutation p-values based on 200,000 simulations per test.

Pairs matched by subject. P-values are from two-tailed tests. 
Table 10: Additional Regressions: The Intermediation Game

\begin{tabular}{|c|c|c|c|c|c|}
\hline & $\begin{array}{c}\text { Subject-Level } \\
\text { Clustering } \\
\text { OLS }\end{array}$ & $\begin{array}{c}\text { Session-Level } \\
\text { Clustering } \\
\text { OLS }\end{array}$ & $\begin{array}{l}\text { Session } \\
\text { R.E. } \\
\text { OLS }\end{array}$ & $\begin{array}{c}\text { Subject } \\
\text { F.E. } \\
\text { OLS }\end{array}$ & $\begin{array}{l}\text { Session } \\
\text { F.E. } \\
\text { OLS }\end{array}$ \\
\hline Dependent Variable & $\begin{array}{c}\text { Punishment } \\
(\$)\end{array}$ & $\begin{array}{c}\text { Punishment } \\
(\$)\end{array}$ & $\begin{array}{c}\text { Punishment } \\
(\$)\end{array}$ & $\begin{array}{c}\text { Punishment } \\
(\$)\end{array}$ & $\begin{array}{c}\text { Punishment } \\
(\$)\end{array}$ \\
\hline & (I) & (II) & (III) & $(\mathrm{IV})$ & $(\mathrm{V})$ \\
\hline $\begin{array}{l}\text { First Mover's Profit }(\$) \\
\text { over } \$ 5\end{array}$ & $\begin{array}{c}0.90^{* * *} \\
(0.09)\end{array}$ & $\begin{array}{c}0.90^{* * *} \\
(0.09)\end{array}$ & $\begin{array}{c}0.90^{* * *} \\
(0.07)\end{array}$ & $\begin{array}{c}0.90^{* * *} \\
(0.04)\end{array}$ & $\begin{array}{c}0.90^{* * *} \\
(0.07)\end{array}$ \\
\hline $\begin{array}{l}\text { First Mover's Profit } \\
\text { over } \$ 5 * \text { Sold }\end{array}$ & $\begin{array}{c}-0.26^{* * *} \\
(0.06)\end{array}$ & $\begin{array}{c}-0.26^{* *} \\
(0.04)\end{array}$ & $\begin{array}{c}-0.26^{* * *} \\
(0.09)\end{array}$ & $\begin{array}{c}-0.26^{* *} \\
(0.05)\end{array}$ & $\begin{array}{c}-0.26^{* * *} \\
(0.09)\end{array}$ \\
\hline Intermediary's Profit & $\begin{array}{c}0.05 \\
(0.02)\end{array}$ & $\begin{array}{c}0.05 \\
(0.03)\end{array}$ & $\begin{array}{l}0.05 \\
(0.05)\end{array}$ & $\begin{array}{l}0.05^{*} \\
(0.03)\end{array}$ & $\begin{array}{l}0.05 \\
(0.05)\end{array}$ \\
\hline Sold Dummy & $\begin{array}{c}0.31^{* * *} \\
(0.08)\end{array}$ & $\begin{array}{l}0.31^{*} \\
(0.11)\end{array}$ & $\begin{array}{c}0.31 \\
(0.28)\end{array}$ & $\begin{array}{c}0.31^{* *} \\
(0.15)\end{array}$ & $\begin{array}{c}0.31 \\
(0.28)\end{array}$ \\
\hline Period & $\begin{array}{l}-0.28 \\
(0.25)\end{array}$ & $\begin{array}{l}-0.28 \\
(0.23)\end{array}$ & $\begin{array}{c}-0.28 * * * \\
(0.05)\end{array}$ & - & $\begin{array}{c}-0.28^{* * *} \\
(0.05)\end{array}$ \\
\hline Constant & $\begin{array}{l}1.12^{* *} \\
(0.70)\end{array}$ & $\begin{array}{c}1.12 \\
(0.49)\end{array}$ & $\begin{array}{c}1.08^{* * *} \\
(0.39)\end{array}$ & $\begin{array}{c}0.43^{* * *} \\
(0.12)\end{array}$ & $\begin{array}{c}1.12^{* * *} \\
(0.26)\end{array}$ \\
\hline
\end{tabular}

Table 11: Expected Payouts in The Intermediation Game

\begin{tabular}{c|cccc}
\hline $\begin{array}{c}\text { Pre-punishment } \\
\text { Wealth }\end{array}$ & $\begin{array}{c}\text { Exp. Payout } \\
\text { Unsold }\end{array}$ & $\begin{array}{c}\text { Exp. Payout } \\
\text { Sold }\end{array}$ & $\begin{array}{c}\text { Ranksum }_{\text {p-value }}{ }^{a} \\
\text {-vermutation }^{\text {p-value }}\end{array}$ \\
\hline \hline$\$ 10$ & $\$ 4.78$ & $\$ 5.70$ & $<0.01$ & 0.01 \\
$\$ 9$ & $\$ 5.00$ & $\$ 5.41$ & 0.05 & 0.07 \\
$\$ 8$ & $\$ 5.11$ & $\$ 5.44$ & 0.07 & 0.06 \\
$\$ 7$ & $\$ 4.97$ & $\$ 4.96$ & 0.61 & 1.00 \\
$\$ 6$ & $\$ 4.70$ & $\$ 4.41$ & 0.48 & 0.13 \\
$\$ 5$ & $\$ 4.31$ & $\$ 3.73$ & $<0.01$ & $<0.01$ \\
\hline \hline
\end{tabular}

Expected Payouts in "sold" column are "worst case" scenarios -

They assume the intermediary will take the action that maximizes expected punishment.

${ }^{a}$ Both tests are two-tailed. Permutation p based on 200,000 permutations. 
Table 12: OLS Regressions

\begin{tabular}{|c|c|c|}
\hline \multicolumn{3}{|c|}{$\begin{array}{l}\text { Subjects Who Expect Intermediation to Hurt Equity } \\
\text { In The Intermediation Game } \\
\qquad \mathrm{N}=46\end{array}$} \\
\hline \multicolumn{3}{|c|}{ Dep. Var. = Punishment $(\$)$} \\
\hline & $\begin{array}{l}\text { All Scenarios } \\
\text { (I) }\end{array}$ & $\begin{array}{l}\text { Intermediary Makes } \$ 0 \\
\text { (II) }\end{array}$ \\
\hline \multirow{2}{*}{$\begin{array}{l}\text { First Mover's Profit }(\$) \\
\text { over } \$ 5\end{array}$} & $0.91^{* * *}$ & $0.91^{* * *}$ \\
\hline & $(0.11)$ & $(0.11)$ \\
\hline \multirow{2}{*}{$\begin{array}{l}\text { First Mover's Profit } \\
\text { over } \$ 5 * \text { Sold }\end{array}$} & $-0.24^{* * *}$ & $-0.14^{* *}$ \\
\hline & $(0.05)$ & $(0.05)$ \\
\hline \multirow[t]{2}{*}{ Intermediary's Profit } & $0.03^{* *}$ & - \\
\hline & $(0.02)$ & \\
\hline \multirow[t]{2}{*}{ Sold Dummy } & $0.26^{* * *}$ & 0.08 \\
\hline & $(0.09)$ & $(0.09)$ \\
\hline \multirow[t]{2}{*}{ Period } & -0.06 & -0.05 \\
\hline & $(0.30)$ & $(0.34)$ \\
\hline \multirow[t]{2}{*}{ Constant } & 1.02 & 1.02 \\
\hline & $(1.15)$ & $(1.29)$ \\
\hline Session F.E. & Included & Included \\
\hline \multicolumn{3}{|c|}{$\begin{array}{l}\text { Standard Errors Clustered at Subject Level } \\
* * *, * *, * \text { indicates } \mathrm{p}<0.01,0.05,0.1 \text { respectively }\end{array}$} \\
\hline
\end{tabular}

Table 13: Punishment for "Wise" Subjects in Reflection Treatment ${ }^{a}$

\begin{tabular}{r|cc|cc|c|c}
\hline \hline & \multicolumn{2}{|c|}{ Avg. Punishment } & \multicolumn{2}{|c|}{ \# Subjects Who Punish } & \multicolumn{2}{|c}{ p-values } \\
\hline $\begin{array}{r}\text { Profit of } \\
\text { First Mover }\end{array}$ & $\begin{array}{c}\text { DG } \\
\text { Unsold }\end{array}$ & $\begin{array}{c}\text { DG } \\
\text { Sold }\end{array}$ & $\begin{array}{c}\text { Unsold } \\
\text { More }\end{array}$ & $\begin{array}{c}\text { Sold } \\
\text { More }\end{array}$ & $\begin{array}{c}\text { Matched Pair, } \\
\text { Signed Rank }^{b}\end{array}$ & $\begin{array}{c}\text { Permutation } \\
\text { Test }^{c}\end{array}$ \\
\hline \hline All & $\$ 2.67$ & $\$ 2.08$ & 23 & 6 & $<0.01$ & $<0.01$ \\
$\$ 10$ & $\$ 5.80$ & $\$ 4.47$ & 6 & 0 & 0.02 & 0.03 \\
$\$ 9$ & $\$ 4.20$ & $\$ 3.40$ & 5 & 2 & 0.21 & 0.25 \\
$\$ 8$ & $\$ 2.93$ & $\$ 2.13$ & 4 & 1 & 0.15 & 0.19 \\
$\$ 7$ & $\$ 1.80$ & $\$ 1.33$ & 5 & 2 & 0.24 & 0.31 \\
$\$ 6$ & $\$ 1.00$ & $\$ 0.80$ & 3 & 1 & 0.16 & 0.50 \\
$\$ 5$ & $\$ 0.33$ & $\$ 0.33$ & 0 & 0 & & 1.00 \\
\hline \hline
\end{tabular}

24 Subjects participated in the Reflection Treatment; 15 were "wise".

${ }^{a}$ To hold outcomes constant, only scenarios where intermediary makes no money included

${ }^{b}$ Matched Pair Signed Rank test based on null hypothesis that punishment distributions are identical for direct and indirect action. Pairs matched by subject.

${ }^{c}$ Permutation p-values based on 200,000 simulations per test.

Pairs matched by subject. P-values are from two-tailed tests. 
Table 14: OLS Regressions: Reflection Treatment

\begin{tabular}{lcc}
\hline \hline \multicolumn{3}{c}{ Dep. Var. = Punishment $(\$)$} \\
\hline \hline & All Subjects & 15 "Wise" Subjects \\
& $(\mathrm{I})$ & $(\mathrm{II})$ \\
\hline First Mover's Profit (\$) & $1.14^{* * *}$ & $1.09^{* * *}$ \\
over $\$ 5$ & $(0.16)$ & $(0.21)$ \\
First Mover's Profit & $-0.33^{* * *}$ & $-0.41^{* * *}$ \\
over $\$ 5 *$ Sold & $(0.10)$ & $(0.12)$ \\
Intermediary's Profit & $0.09^{* * *}$ & 0.04 \\
& $(0.03)$ & $(0.03)$ \\
Sold Dummy & 0.10 & $0.39^{*}$ \\
& $(0.29)$ & $(0.20)$ \\
Period & -0.42 & -0.29 \\
& $(0.31)$ & $(0.38)$ \\
Constant & 1.31 & 1.25 \\
& $(0.97)$ & $(1.31)$ \\
\hline Standard Errors Clustered at Subject Level & \\
$* * *, * *, *$ indicates $\mathrm{p}<0.01,0.05,0.1$ respectively & \\
\hline
\end{tabular}

Table 15: Survey 1 Summary Stats \& Randomization

\begin{tabular}{rccc}
\hline & Pooled & Direct & Indirect \\
\hline Observations & 202 & 108 & 94 \\
Gender (Male=1, Female=0) & 0.31 & 0.33 & 0.35 \\
Freshman & 0.33 & 0.36 & 0.30 \\
Sophomore & 0.32 & 0.33 & 0.30 \\
Junior & 0.31 & 0.27 & 0.36 \\
Senior & 0.03 & 0.04 & 0.02 \\
Member of Charity Group (PBHA) & 0.59 & 0.60 & 0.59 \\
\hline
\end{tabular}

Table 16: Survey 2 Summary Stats \& Randomization

\begin{tabular}{rccccc}
\hline & Pooled & Direct, Reward & Indirect, Reward & Direct, Guess & Indirect, Guess \\
\hline Observations & 135 & 42 & 31 & 31 & 31 \\
Gender (Male=1) & 0.35 & 0.40 & 0.29 & 0.35 & 0.35 \\
Freshman & 0.30 & 0.21 & 0.39 & 0.26 & 0.39 \\
Sophomore & 0.27 & 0.36 & 0.29 & 0.23 & 0.16 \\
Junior & 0.39 & 0.31 & 0.32 & 0.52 & 0.42 \\
Senior & 0.02 & 0.05 & 0.00 & 0.00 & 0.03 \\
PBHA & 0.64 & 0.67 & 0.65 & 0.68 & 0.55 \\
\hline
\end{tabular}




\section{References}

[1] Foot, Philippa. 1978. Virtues and Vices and Other Essays, Berkeley. California: University of California Press.

[2] Greene, Joshua D and Jonathan Haidt. 2002. "How (and where) Does Moral Judgment Work?" TRENDS in Cognitive Sciences, 16(12): 517-523. 


\title{
The Intermediation Game (and Reflection Treatment)
}

Experimental Instructions, accompanying slideshow and script.

\author{
Text in RED has been added
}




\section{Experiment Instructions}

\section{Preliminaries}

Thank you for participating in this study. If at any time you have questions, please raise your hand, and I will assist you. From now until the end of the session, communication of any kind between participants is not allowed. Please do not use the computer for any other purpose than participating in this study. Also, please turn off your cell phones.

\section{Overview}

The purpose of this session is to study decision making.

You will make a series of decisions that will affect your payoffs as well as the payoffs of others.

All studies run here in the Computer Lab for Experimental Research (CLER) do NOT use deception. Everything in these instructions is true, including the rules and the payoffs. Everyone received the same instructions.

What are my payoffs?

You will be paid your $\$ 10$ show up fee plus the money made during the course of the following game.

As an example just for illustrative purposes: If you make $\$ 5$ in the game, you will be paid \$15 total.

\section{The Game}

The game will be played in groups of four. We will play the game four times. Each time we play the game will be referred to as a "period".

In each period, everyone will be randomly assigned to one role and one group. You will play each role exactly once.

There are no computer players. The other three players in your group will be three other people in the room. You will be playing with three different people in each period.

Let's call the four roles A, B, C, and D. The game is completely anonymous, so players will only be referred to as A, B, C, or D for the duration of the experiment.

Here is how the game works:

Player A owns the rights to split $\$ 10$ with C. That

is, A decides how to split the $\$ 10$, and the two players are paid accordingly. C has no say in the decision. C will simply be informed of A's anonymous decision.
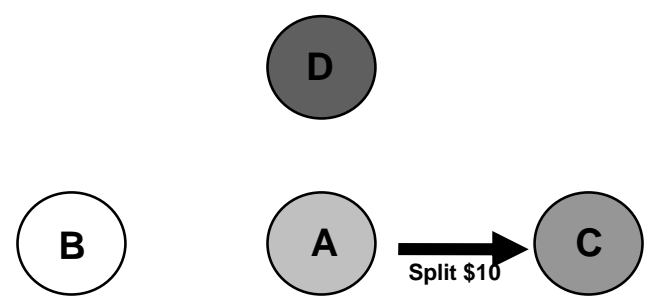

Show slides 2 and 3 with script. 


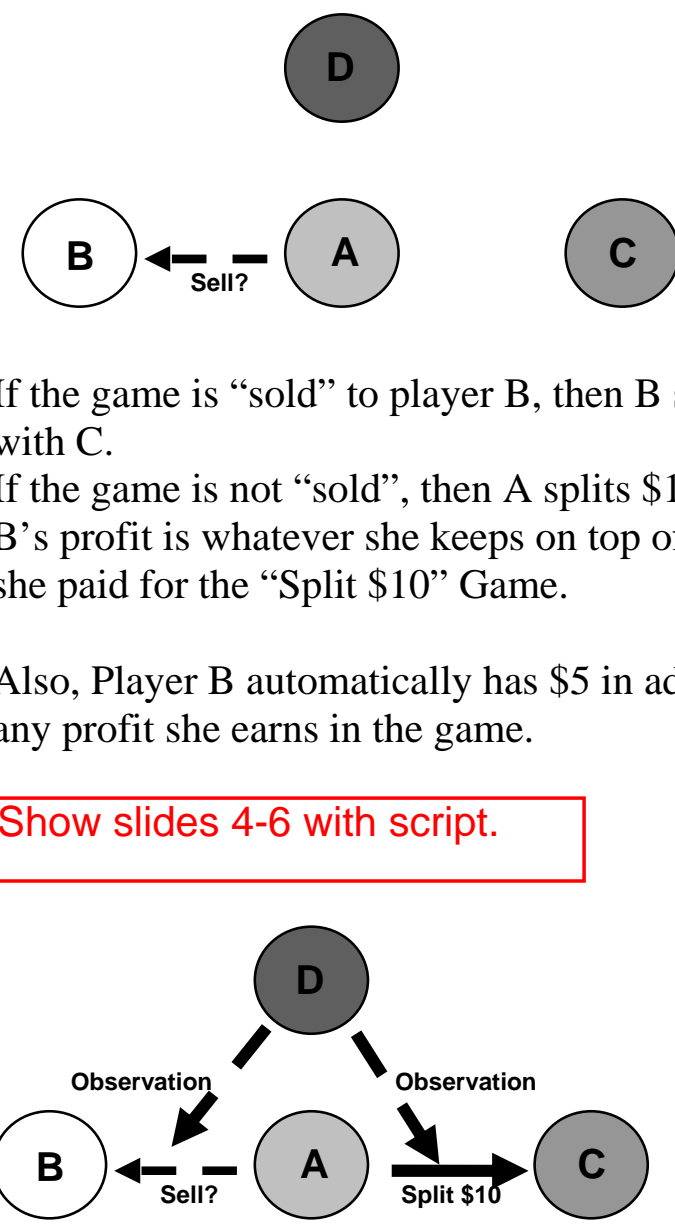

Before A splits the \$10 however, A can "sell” the rights to play this game to player B.

A chooses whether to sell, and how much to sell for. B has no say in the decision.

If the game is "sold" to player B, then B splits $\$ 10$ with C.

If the game is not "sold", then A splits $\$ 10$ with C.

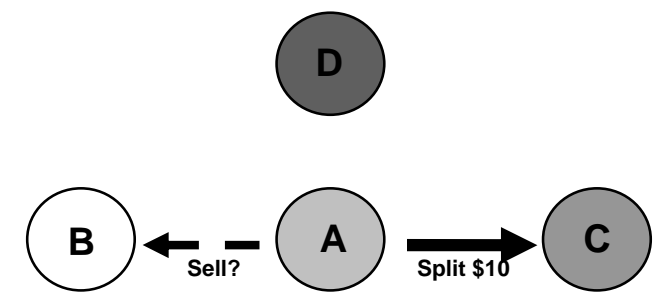

Also, Playe B automaticaly has $\$ 5$ in addition to any profit she earns in the game.

Player D then has the option of reducing Player A's payoff. They get to make this decision based on what happened in the game:

1 . Whether the game was sold

2. If so, for how much

3. How was the $\$ 10$ split with Player C

Player D can reduce Player A's payoff by any amount; However, she cannot reduce Player A to negative amounts.

So say Player A makes $\$ 7$ (either by selling or playing the "Split \$10" Game). Player D can punish any amount between $\$ 0$ and $\$ 7$.

Player D earns exactly $\$ 5$ for the period no matter what punishment decisions she makes.

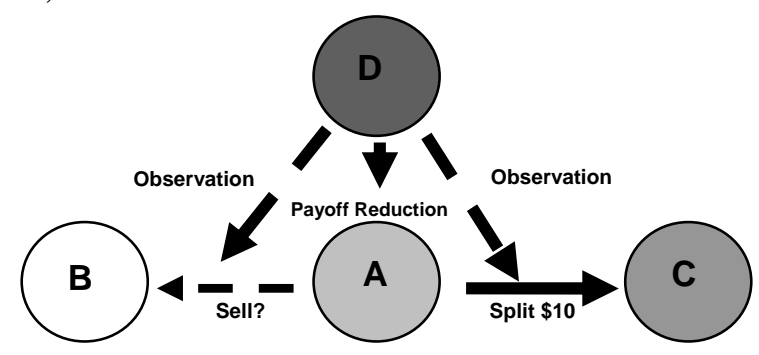
Show slides 7 and 8 with script.

At the end of each period, you will not be told the decisions of the other players. We will learn what happened once we have played all four periods.

At that point, the computer will randomly choose one period. Your profits from that period, and that period only, will be the amount that you are paid when you leave, in addition to your show up fee.

Everyone will be paid for the same period. All four periods are equally likely to be the "payment period", so make thoughtful decisions in all four periods. 
To recap, broken down by roles, the game is as follows:

Player A

- Owns the rights to anonymously split \$10 with C, without any input from C

- Can "sell” this to B

- Can be punished by D

- If A sells the Split \$10 game to B, Profit is equal to the price for which the game sells minus the punishment decided by $\mathrm{D}$.

- If A does not sell the Split \$10 game, Profit is equal to the amount A keeps in the "Split \$10" game minus the punishment decided by D.

Player $B$

- Can purchase from A the rights to anonymously split \$10 with C, without any input from $\mathrm{C}$

- Cannot be punished by D

- If B is sold the Split \$10 game by A, Profit is equal to the amount kept in the game minus the price paid for the game.

- $\quad$ If B is not sold the Split $\$ 10$ game by A, Profit is 0 .

- Will be paid $\$ 5$ plus any profits made in this game.

Player C

- Receives the amount that is decided by A or B. This is C's Profit.

Player D

- Based on the behavior of A and B, D can reduce A's payoff by any amount all the way to $\$ 0$.

- Profit equals \$5 no matter what.

\section{Are there any questions about how this game works?}

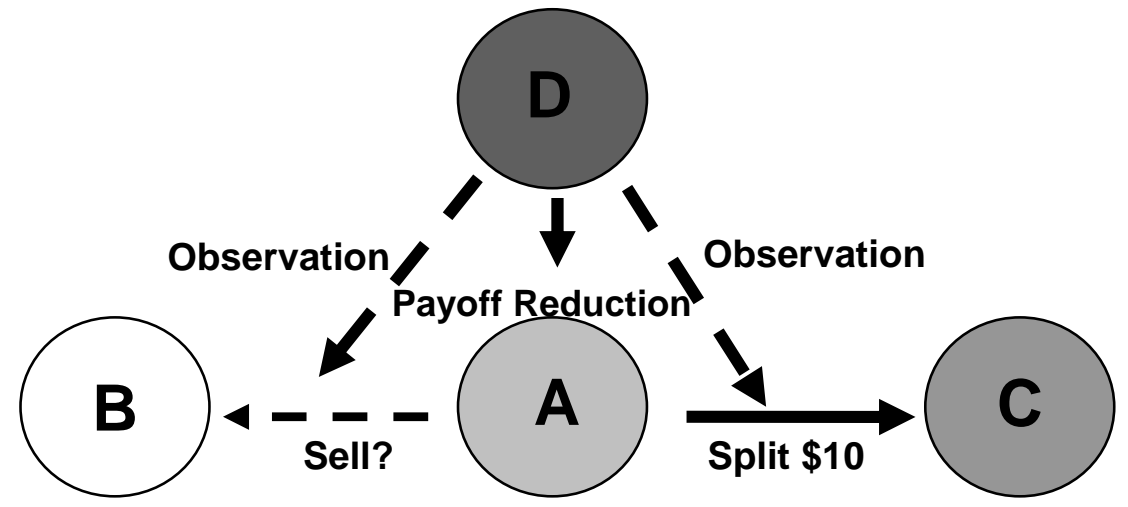

If at any time during the session you have questions, please raise your hand.

Good luck. 


\section{Welcome}

Please read and sign the consent forms.

We'll go through the instructions together. 


\section{The "Split \$10" Game}
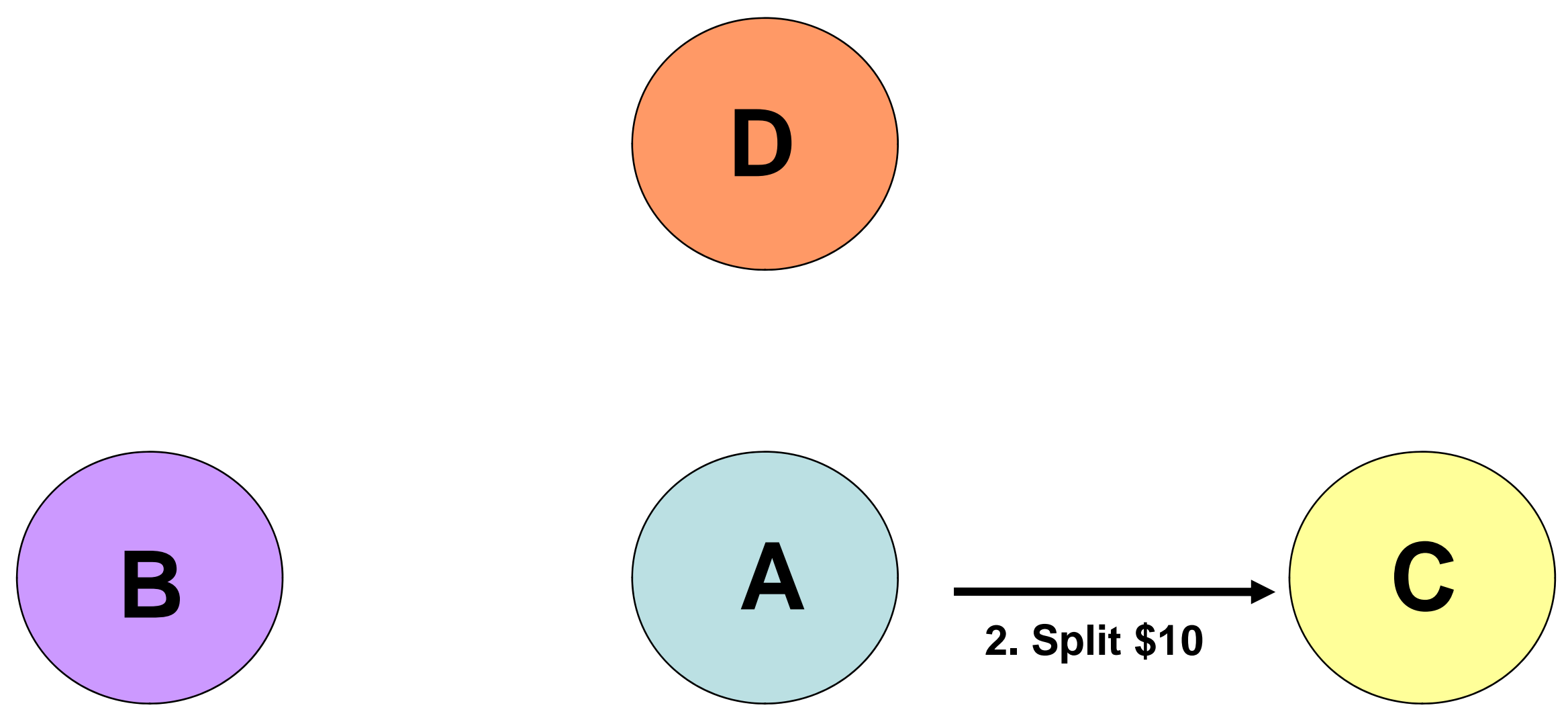
$C \$ 5$ for you, $\$ 5$ for Person $C$

C $\$ 6$ for you, $\$ 4$ for Person $C$

C $\$ 7$ for you, $\$ 3$ for Person $C$

C $\$ 8$ for you, $\$ 2$ for Person $C$

C $\$ 9$ for you, $\$ 1$ for Person $C$

C $\$ 10$ for you, $\$ 0$ for Person $C$ 


\section{"Sell"}
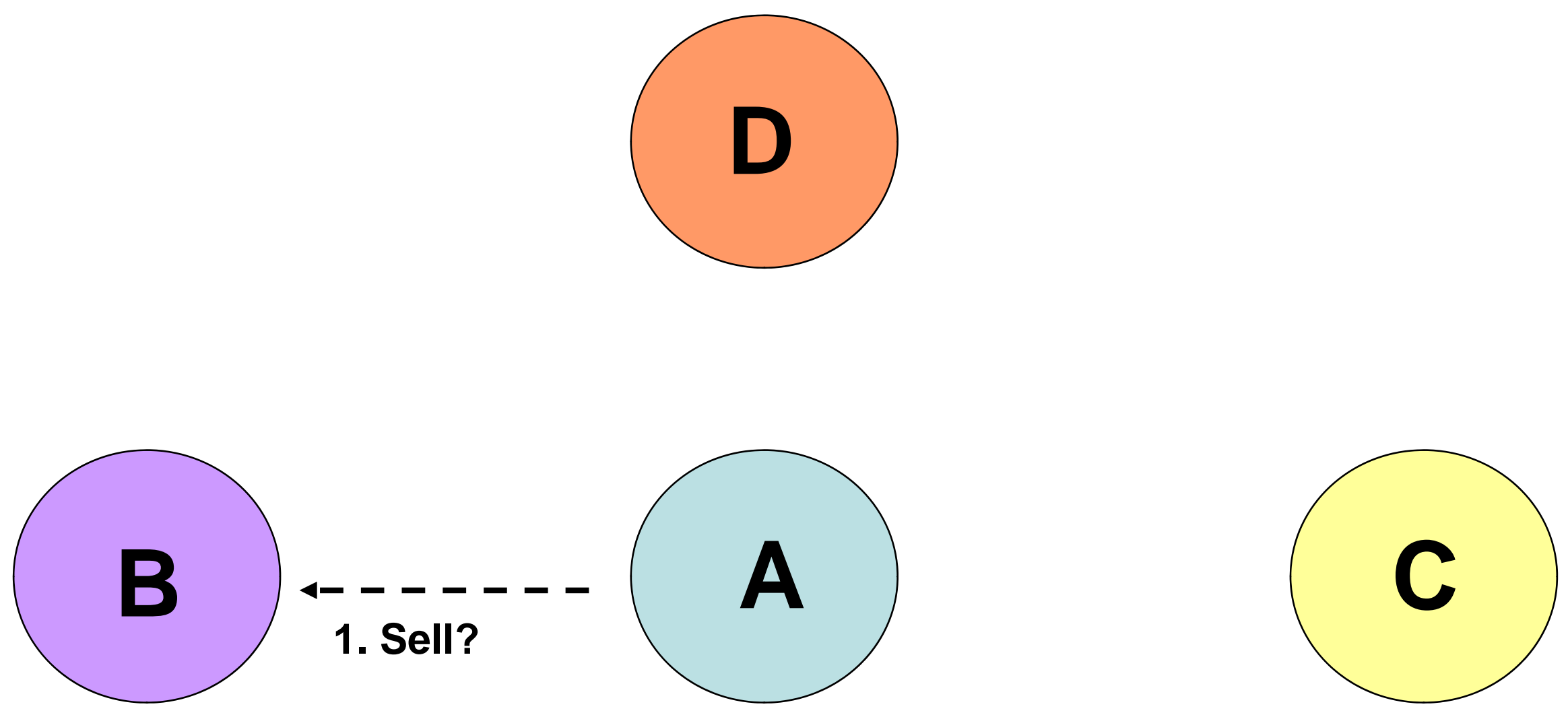
You own the rights to split $\mathbf{\$ 1 0}$ with Person $\mathrm{C}$. You will both be paid according to how you decide to split the $\$ 10$.

However, you can sell these rights now if you wish.

If you sell the rights, your profit will be the price you sell them for. If you do not sell them, your profit will be the amount of the $\$ 10$ you decide to keep.

Keep in mind, though, that Person D will be notified of all of your actions and will have the opportunity to reduce your profits.

Would you like to sell the "Split \$10" game?

No, Play the Split $\$ 10$ Game Myself

C Yes, Sell the Game to Player B 
You have chosen to sell the "Split $\$ 10$ " Game.

Choose how much you are selling it for:

$$
\begin{aligned}
& C \$ 10 \\
& C \$ 9 \\
& C \$ 8 \\
& C \$ 7 \\
& C \$ 6 \\
& C \$ 5
\end{aligned}
$$




\section{Punishment}

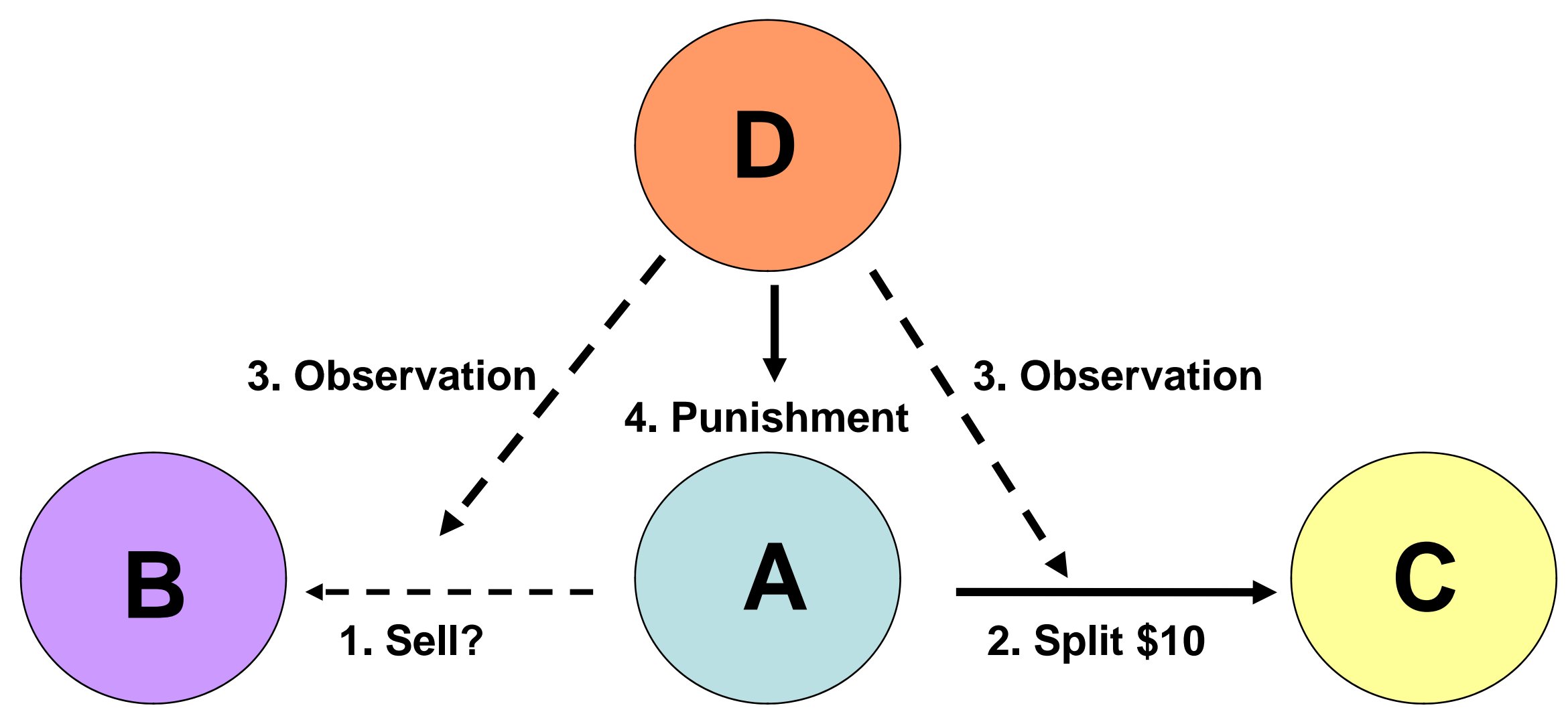


Suppose Person A sold the "Split \$10" game for $\$ 6$ to Person B.

And PERSON B kept $\$ 10$ and gave Person C \$0.

How much would you like to reduce PERSON A's payoff?

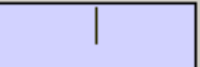




\section{Questions?}

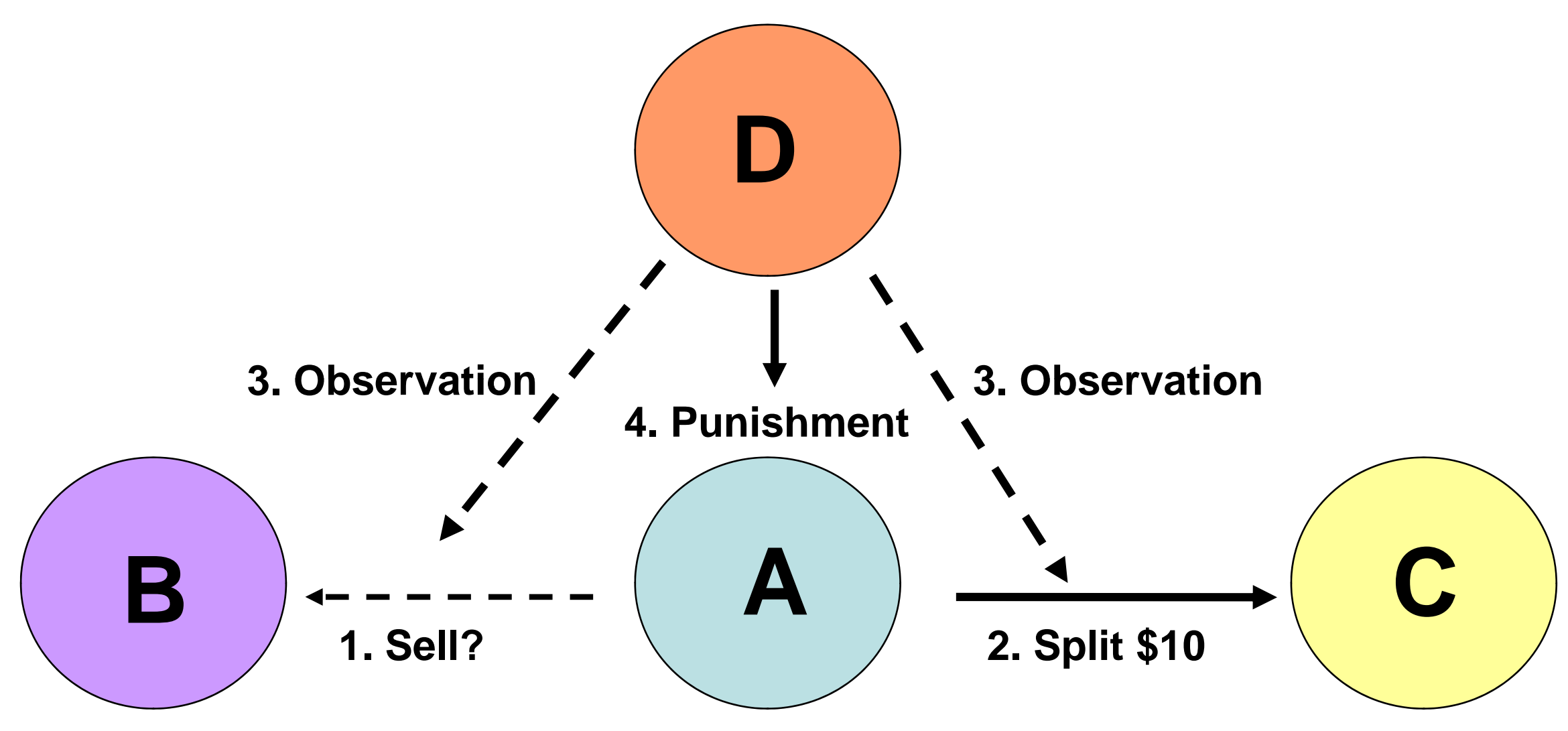




\section{Intermediation Game - Script}

Below is the script that accompanied the slideshow that accompanied the instructions. As with the instructions, the script was read aloud by the experimenter to all subjects simultaneously.

Where the slides are used is noted in the included instructions in red.

$\underline{\text { Slide } 2}$

Let's see what the Split $\$ 10$ Game will look like when you actually play the game.

$\underline{\text { Slide } 3}$

If you play the Split $\$ 10$ Game, this is the screen you will see.

There are 6 ways you can split the $\$ 10$, and they are listed here.

$\$ 5$ for you, $\$ 5$ for person C. $\$ 6$ for you, $\$ 4$ for person C. $\$ 7$ for you, $\$ 3$ for person C.

$\$ 8$ for you, $\$ 2$ for person C. $\$ 9$ for you, $\$ 1$ for person C. $\$ 10$ for you, $\$ 0$ for person C. You highlight the radio button of the allocation you desire and hit "Done".

Person $\mathrm{C}$ will not see this screen. They will only be told of your anonymous decision at the end of the experiment.

\section{$\underline{\text { Slide } 4}$}

Let's see what the sell decision will look like when you actually play the game.

\section{$\underline{\text { Slide } 5}$}

If you are player $\mathrm{A}$, this is the first screen you will see.

First, it recaps everything you already know from the instructions.

Then it asks if you would like to sell the Split $\$ 10$ Game.

If you select "No", you will play the Split $\$ 10$ Game as we just saw.

If you select "Yes", you will then see the pricing screen...

\section{$\underline{\text { Slide } 6}$}

... which looks like this.

You can sell the game for $\$ 5, \$ 6, \$ 7, \$ 8, \$ 9$ or $\$ 10$. Select the amount you want and hit "Sell".

Then, Player B plays the Split $\$ 10$ Game that we saw.

However, she must keep at least as much as she was forced to pay for the game. That is, if Player A sells her the Split $\$ 10$ Game for $\$ 8$ (Point to $\$ 8$ ), Player B must keep $\$ 8, \$ 9$, or $\$ 10$. Her profit is anything she keeps above $\$ 8$, and this is added to the $\$ 5$ she started with. 


\section{$\underline{\text { Slide } 7}$}

Let's see what the punishment decision will look like when you actually play the game. When you are Player D, we are going to ask for your punishment decision for every possible scenario in the game between A, B, and C. Whichever one actually happens, we will reduce Player A's payout by the amount you decided for that scenario.

\section{$\underline{\text { Slide } 8}$}

Here's one example, just for illustration.

It says, "Suppose Person A sold the 'Split $\$ 10$ ' game for $\$ 6$ to Person B. And Person B kept $\$ 10$ and gave Person C $\$ 0$."

And then it asks how much you would like to reduce Person A's payout. Enter the dollar amount by which you would like to reduce A's payout.

You can reduce A by any amount you want, all the way to $\$ 0$. So in this example, A made $\$ 6$, so you can enter any number between 0 and 6 in the box.

And if the Person A in your group DID sell the game for $\$ 6$ and Person B subsequently kept $\$ 10$, then we would reduce A's payout by the number that you enter here.

There are 27 possible scenarios. We will ask you each, one at a time, in a random order.

\section{$\underline{\text { Slide } 9}$}

The last page is a summary broken down by role. Please review that and raise your hand if you have a question. We'll take a few minutes to answer all questions, and then we'll begin the game. 
No Intermediary Treatment

Experimental Instructions, accompanying slideshow and script. 


\section{Experiment Instructions}

\section{Preliminaries}

Thank you for participating in this study. If at any time you have questions, please raise your hand, and I will assist you. Please do not ask questions aloud. From now until the end of the session, communication of any kind between participants is not allowed.

Please do not use the computer for any other purpose than participating in this study. Also, please turn off your cell phones.

\section{Overview}

The purpose of this session is to study decision making.

You will make a series of decisions that will affect your payoffs as well as the payoffs of others.

All studies run here in the Computer Lab for Experimental Research (CLER) do NOT use deception. Everything in these instructions is true, including the rules and the payoffs. Everyone received the same instructions.

What are my payoffs?

You will be paid your $\$ 10$ show up fee plus the money made during the course of the following game.

As an example just for illustrative purposes: If you make $\$ 5$ in the game, you will be paid $\$ 15$ total.

\section{The Game}

The game will be played in groups of three. We will play the game three times. Each time we play the game will be referred to as a "period".

In each period, everyone will be randomly assigned to one role and one group. You will play each role exactly once.

There are no computer players. The other two players in your group will be two other people in the room. You will be playing with two different people in each period.

Let's call the three roles A, B, and C. The game is completely anonymous, so players will only be referred to as $\mathrm{A}, \mathrm{B}$, or $\mathrm{C}$ for the duration of the experiment.

Here is how the game works:

Player A is going to split $\$ 10$ with Player B. That is, A decides how to split the $\$ 10$, and the two players are paid accordingly. B has no say in the decision. B will simply be informed of A's anonymous decision afterwards.

Show slides 2 and 3 with script.
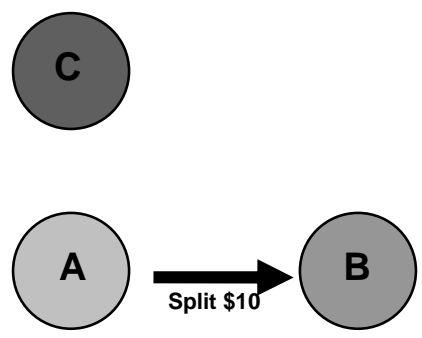


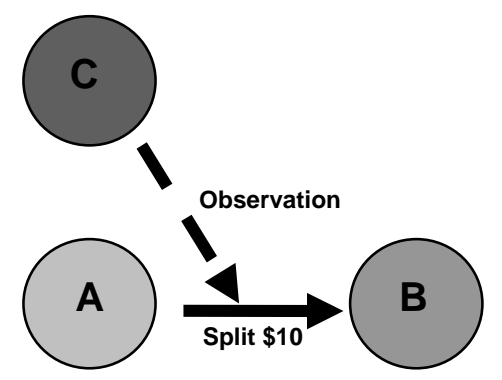

Player C then chooses how much to reduce Player A's payoff. C gets to make this decision based on how much of the $\$ 10$ A kept for herself.

How the punishment works is very simple.

Player $\mathrm{C}$ sees how player A behaved in the game.

Player C can then reduce Player A's earnings as much as he/she wants, all the way to $\$ 0$.

For illustrative purposes only, say Player A kept \$7, thus sending Player B \$3.

In that scenario, Player $C$ can reduce Player's A's payoff by any amount between $\$ 0$ and $\$ 7$.

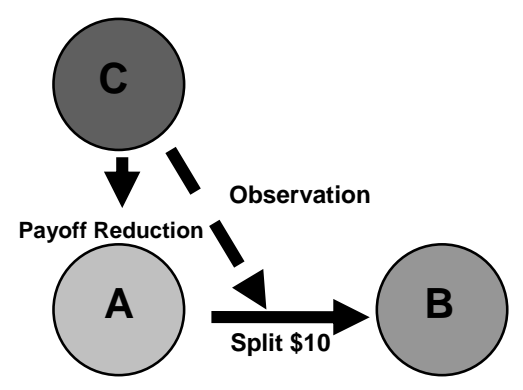

C cannot reduce B's payoff.

Player $C$ is paid $\$ 5$ no matter what happens in the game or what punishment decisions he/she makes.

Show slides 4 and 5 with script.

At the end of each period, you will not be told the decisions of the other players. We will learn what happened once we have played all three periods.

At that point, the computer will randomly choose one period. Your profits from that period, and that period only, will be the amount that you are paid when you leave, in addition to your show up fee.

Everyone will be paid for the same period. All three periods are equally likely to be the "payment period", so make thoughtful decisions in all three periods. 
To recap, broken down by roles, the game is as follows:

\section{Player A}

- Will anonymously split \$10 with B, without any input from B

- Can be punished by $\mathrm{C}$

- Profit is equal to the amount A keeps in the "Split \$10" game minus the punishment decided by $\mathrm{C}$.

\section{Player B}

- Receives the amount that is decided by A. This is B's Profit.

\section{Player C}

- Based on the behavior of A, C can reduce A's payoff by as much as she wants, all the way to $\$ 0$.

- Player C is paid \$5 no matter what happens in the game or what punishment decisions she makes.

\section{Are there any questions about how this game works?}

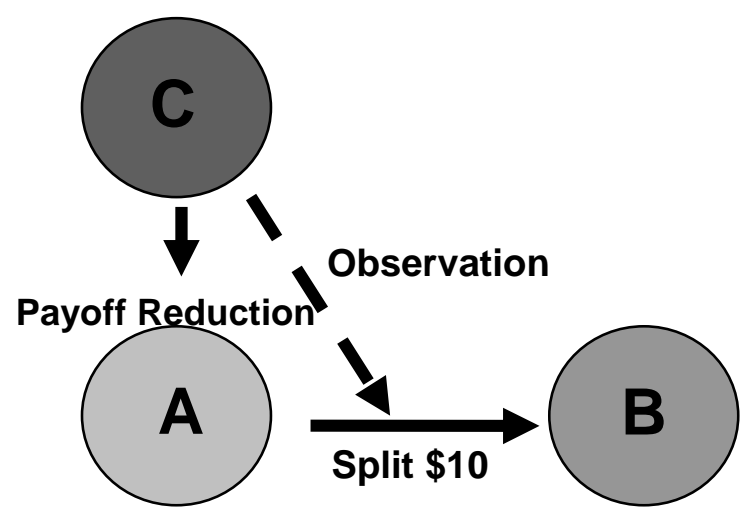

If at any time during the session you have questions, please raise your hand.

Good luck. 


\section{Welcome}

Please read and sign the consent forms.

We'll go through the instructions together. 


\section{The "Split \$10" Game}
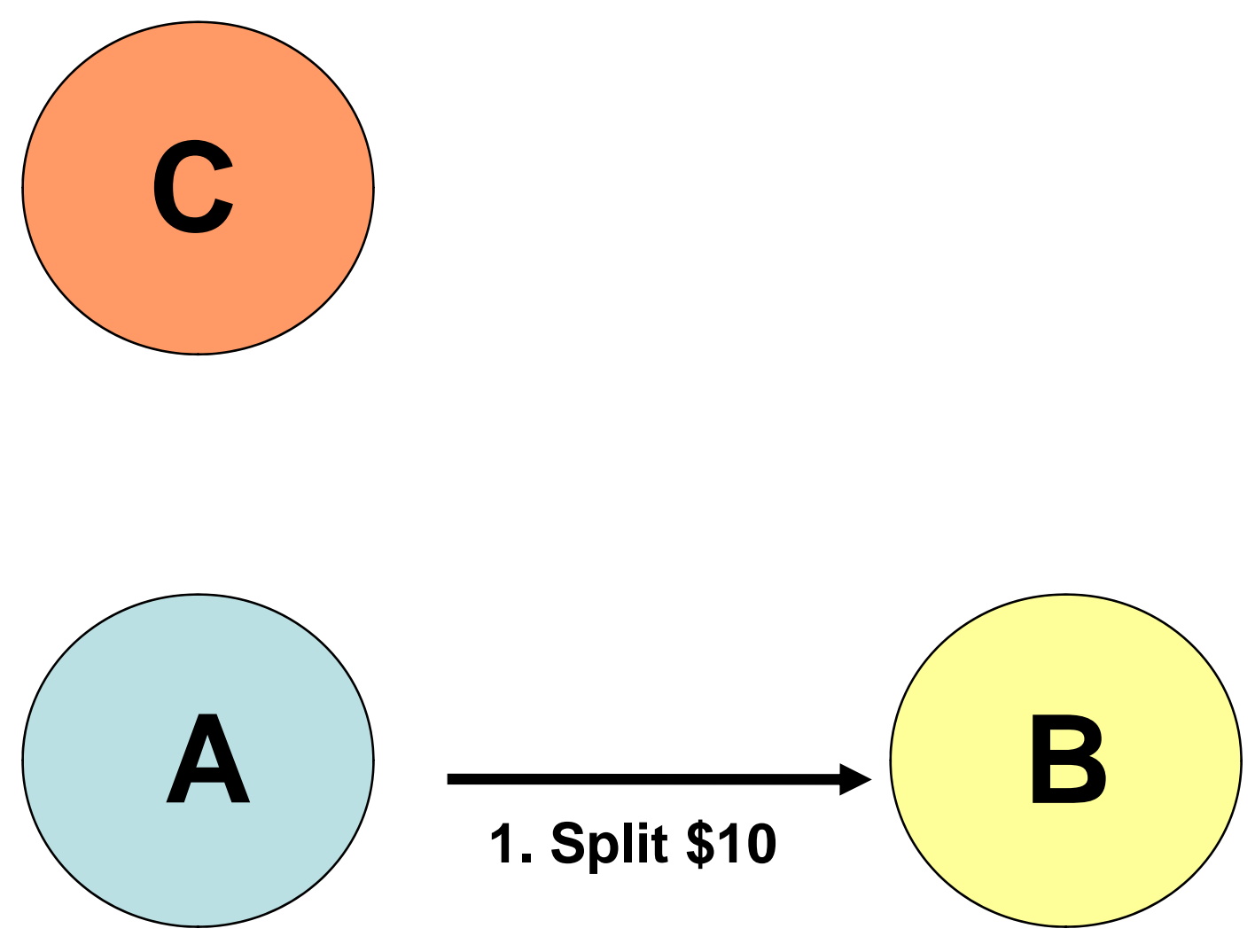
$C \$ 5$ for you, $\$ 5$ for Person $C$

C $\$ 6$ for you, $\$ 4$ for Person $C$

C $\$ 7$ for you, $\$ 3$ for Person $C$

C $\$ 8$ for you, $\$ 2$ for Person $C$

C $\$ 9$ for you, $\$ 1$ for Person $C$

C $\$ 10$ for you, $\$ 0$ for Person $C$ 


\section{Punishment}

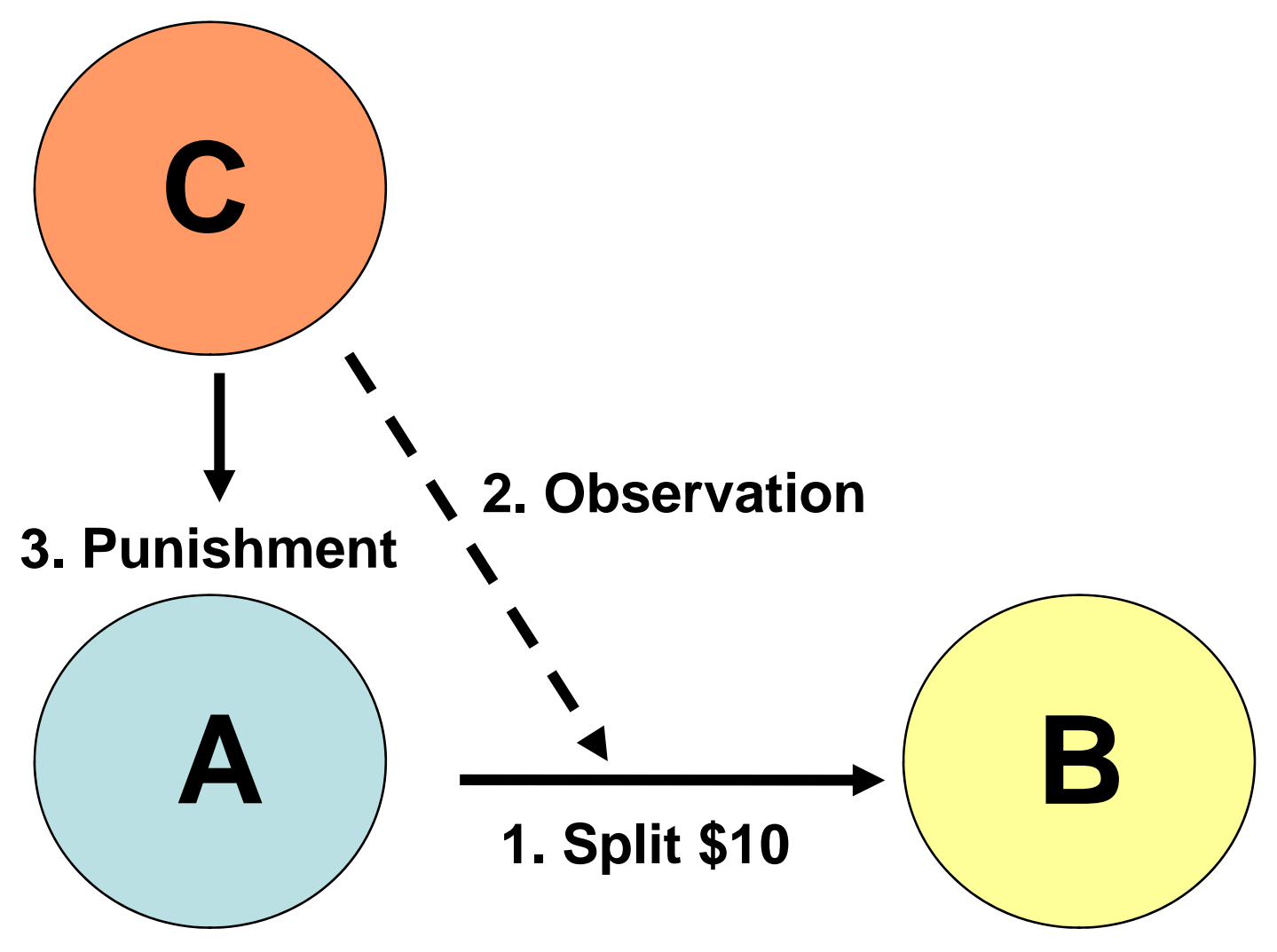




\section{Suppose Person A kept \$8 and gave Person B \$2.}

How much would you like to reduce PERSON A's payoff?

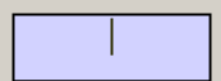




\section{Questions?}

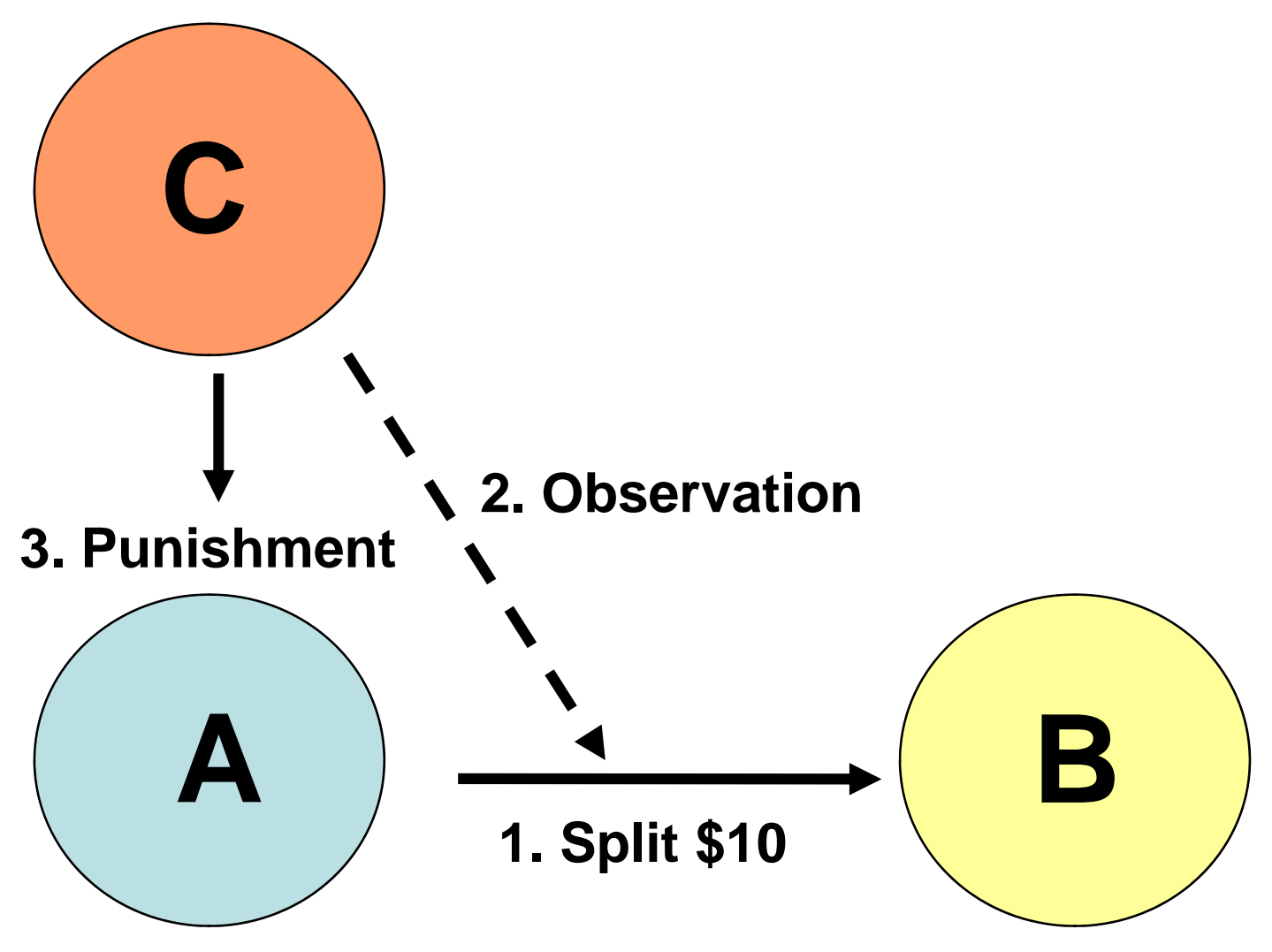




\section{No Intermediary Treatment - Script}

Below is the script that accompanied the slideshow that accompanied the instructions. As with the instructions, the script was read aloud by the experimenter to all subjects simultaneously.

Where the slides are used is noted in the included instructions in red.

$\underline{\text { Slide } 2}$

Let's see what the Split $\$ 10$ Game will look like when you actually play the game.

$\underline{\text { Slide } 3}$

If you play the Split $\$ 10$ Game, this is the screen you will see.

There are 6 ways you can split the $\$ 10$, and they are listed here.

$\$ 5$ for you, $\$ 5$ for person C. $\$ 6$ for you, $\$ 4$ for person C. $\$ 7$ for you, $\$ 3$ for person C.

$\$ 8$ for you, $\$ 2$ for person C. $\$ 9$ for you, $\$ 1$ for person C. $\$ 10$ for you, $\$ 0$ for person C. You highlight the radio button of the allocation you desire and hit "Done".

Person $\mathrm{C}$ will not see this screen. They will only be told of your anonymous decision at the end of the experiment.

\section{$\underline{\text { Slide } 4}$}

Let's see what the punishment decision will look like when you actually play the game. When you are Player D, we are going to ask for your punishment decision for every possible scenario in the game between $\mathrm{A}$ and $\mathrm{B}$. Whichever one actually happens, we will reduce Player A's payout by the amount you decided for that scenario.

\section{$\underline{\text { Slide } 5}$}

Here's one example. It says, "Suppose Person A kept $\$ 8$ and gave Person B $\$ 2 "$. And then it asks how much you would like to reduce Person A's payout. Enter the dollar amount by which you would like to reduce A's payout.

You can reduce A by any amount you want, all the way to $\$ 0$. So in this example, A made $\$ 8$, so you can enter any number between 0 and 8 in the box.

In this case, if the Person A in your group DID keep $\$ 8$, then we would reduce A's payout by the number that you enter here.

There are 6 possible scenarios. We will ask you each, one at a time, in a random order.

$\underline{\text { Slide } 6}$

The last page is a summary broken down by role. Please review that and raise your hand if you have a question. We'll take a few minutes to answer all questions, and then we'll begin the game. 


\section{Two Punishments Treatment}

Experimental Instructions, accompanying slideshow and script. 


\section{Experiment Instructions}

\section{Preliminaries}

Thank you for participating in this study. If at any time you have questions, please raise your hand, and I will assist you. From now until the end of the session, communication of any kind between participants is not allowed. Please do not use the computer for any other purpose than participating in this study. Also, please turn off your cell phones.

\section{Overview}

The purpose of this session is to study decision making.

You will make a series of decisions that will affect your payoffs as well as the payoffs of others.

All studies run here in the Computer Lab for Experimental Research (CLER) do NOT use deception. Everything in these instructions is true, including the rules and the payoffs. Everyone received the same instructions.

What are my payoffs?

You will be paid your $\$ 10$ show up fee plus the money made during the course of the following game.

As an example just for illustrative purposes: If you make $\$ 5$ in the game, you will be paid \$15 total.

\section{The Game}

The game will be played in groups of four. We will play the game four times. Each time we play the game will be referred to as a "period".

In each period, everyone will be randomly assigned to one role and one group. You will play each role exactly once.

There are no computer players. The other three players in your group will be three other people in the room. You will be playing with three different people in each subsequent period.

Let's call the four roles A, B, C, and D. The game is completely anonymous, so players will only be referred to as A, B, C, or D for the duration of the experiment.

Here is how the game works:

Player A owns the rights to split $\$ 10$ with C. That

is, A decides how to split the $\$ 10$, and the two players are paid accordingly. C has no say in the decision. C will simply be informed of A's anonymous decision.

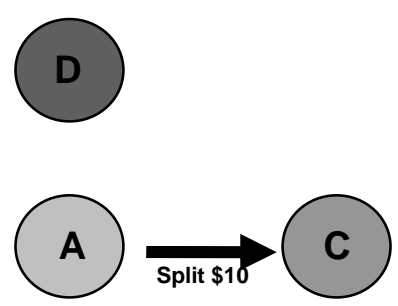

Show slides 2 and 3 with script. 


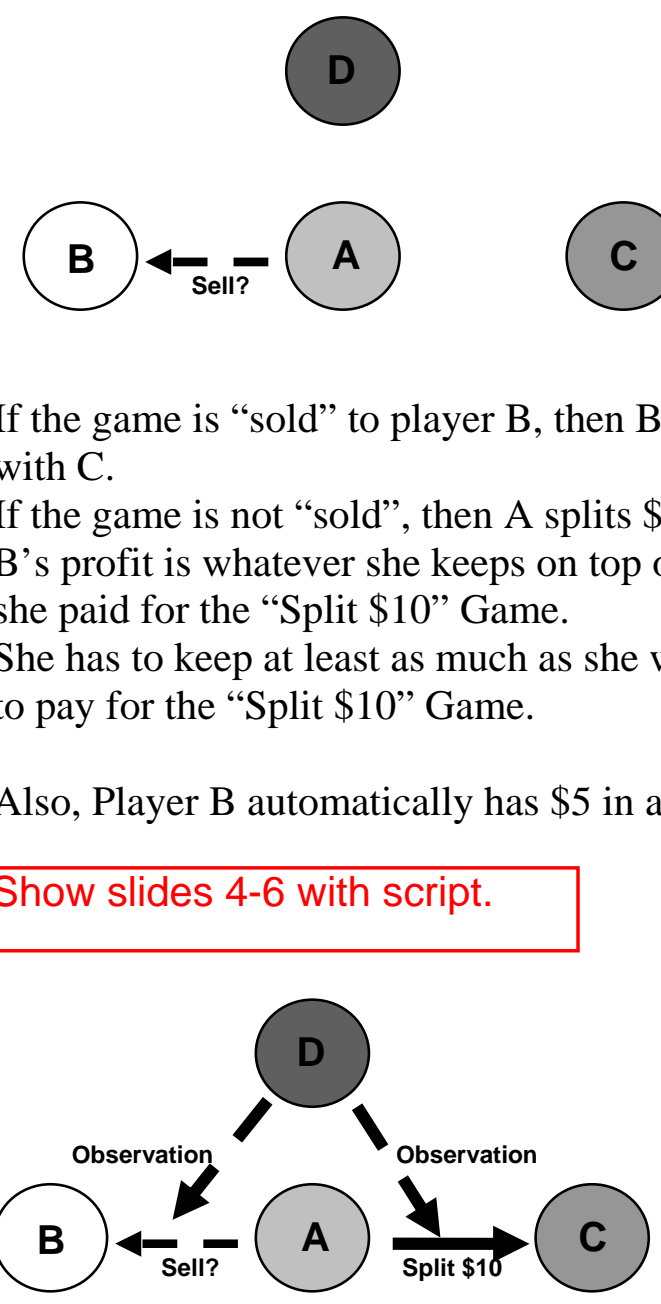

Player D then has the option of reducing Player A's and Player B's payoffs. They get to make this decision based on what happened in the game:

1. Whether the game was sold

2. If so, for how much

3. How was the $\$ 10$ split with Player $C$

Player D can reduce Player A's and/or Player B's payoff by any amount; However, she cannot reduce either to a negative amount.

So say Player A makes $\$ 7$ (either by selling or playing the "Split \$10" Game). Player D can punish any amount between $\$ 0$ and $\$ 7$.

Similarly, if Player B earns $\$ 3$ in the game, she has $\$ 8$ total since she starts with $\$ 5$, so Player D can punish any amount between $\$ 0$ and $\$ 8$.

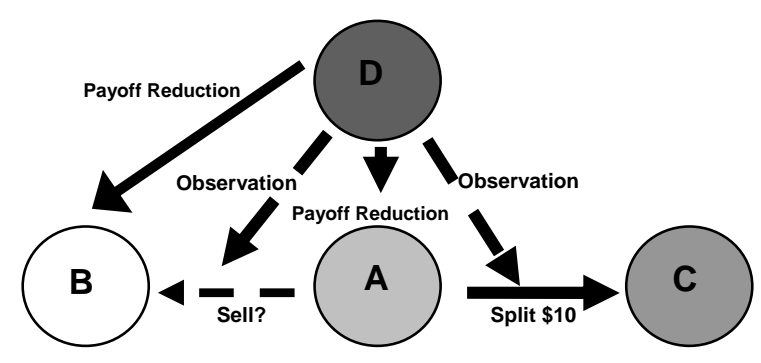
They can be reduced by different amounts. Player D can choose to reduced one, both or neither of the players.

Player D earns exactly $\$ 5$ for the period no matter what punishment decisions she makes.

Show slides 7 and 8 with script. 
At the end of each period, you will not be told the decisions of the other players. We will learn what happened once we have played all four periods.

At that point, the computer will randomly choose one period. Your profits from that period, and that period only, will be the amount that you are paid when you leave, in addition to your show up fee.

Everyone will be paid for the same period. All four periods are equally likely to be the “payment period”, so make thoughtful decisions in all four periods. 
Show slide 9 with script

To recap, broken down by roles, the game is as follows:

Player A

- Owns the rights to anonymously split \$10 with C, without any input from C

- Can "sell” this to B

- Can be punished by D

- If A sells the Split \$10 game to B, Profit is equal to the price for which the game sells minus the punishment decided by $\mathrm{D}$.

- If A does not sell the Split \$10 game, Profit is equal to the amount A keeps in the "Split \$10" game minus the punishment decided by D.

Player $B$

- Can purchase from A the rights to anonymously split \$10 with C, without any input from $\mathrm{C}$

- Can be punished by $\mathrm{D}$

- If B is sold the Split \$10 game by A, Profit is equal to the amount kept in the game minus the price paid for the game minus punishment.

- If B is not sold the Split $\$ 10$ game by A, Profit is $\$ 0$ minus punishment.

Player C

- Will be paid $\$ 5$ plus any profits made in this game.

- Receives the amount that is decided by A or B. This is C's Profit.

Player D

- Based on the behavior of A and B, D can reduce their payoffs by any amount all the way to $\$ 0$.

- Profit equals \$5 no matter what.

\section{Are there any questions about how this game works?}

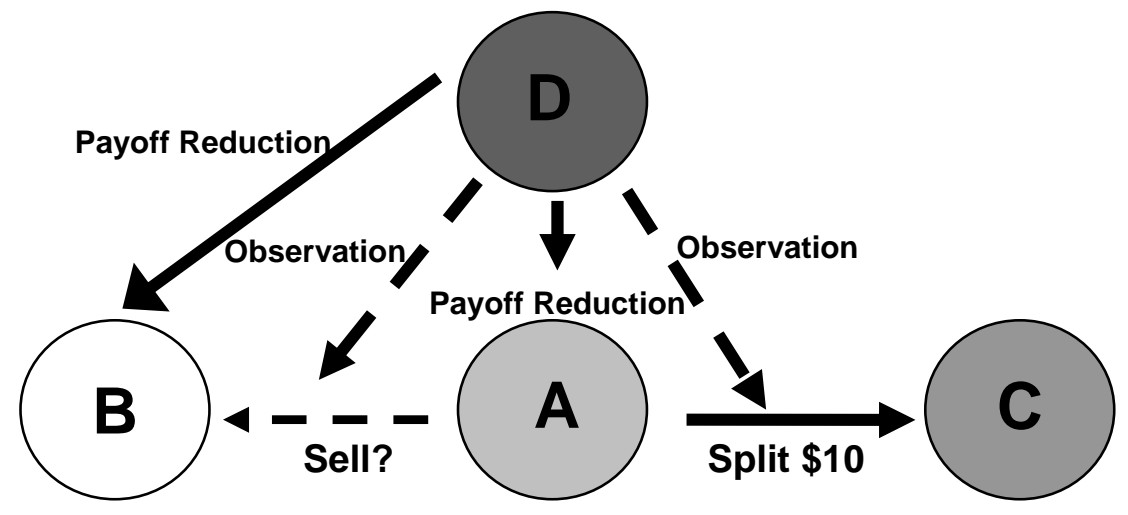

If at any time during the session you have questions, please raise your hand.

Good luck. 


\section{Welcome}

Please read and sign the consent forms.

We'll go through the instructions together. 


\section{The "Split \$10" Game}
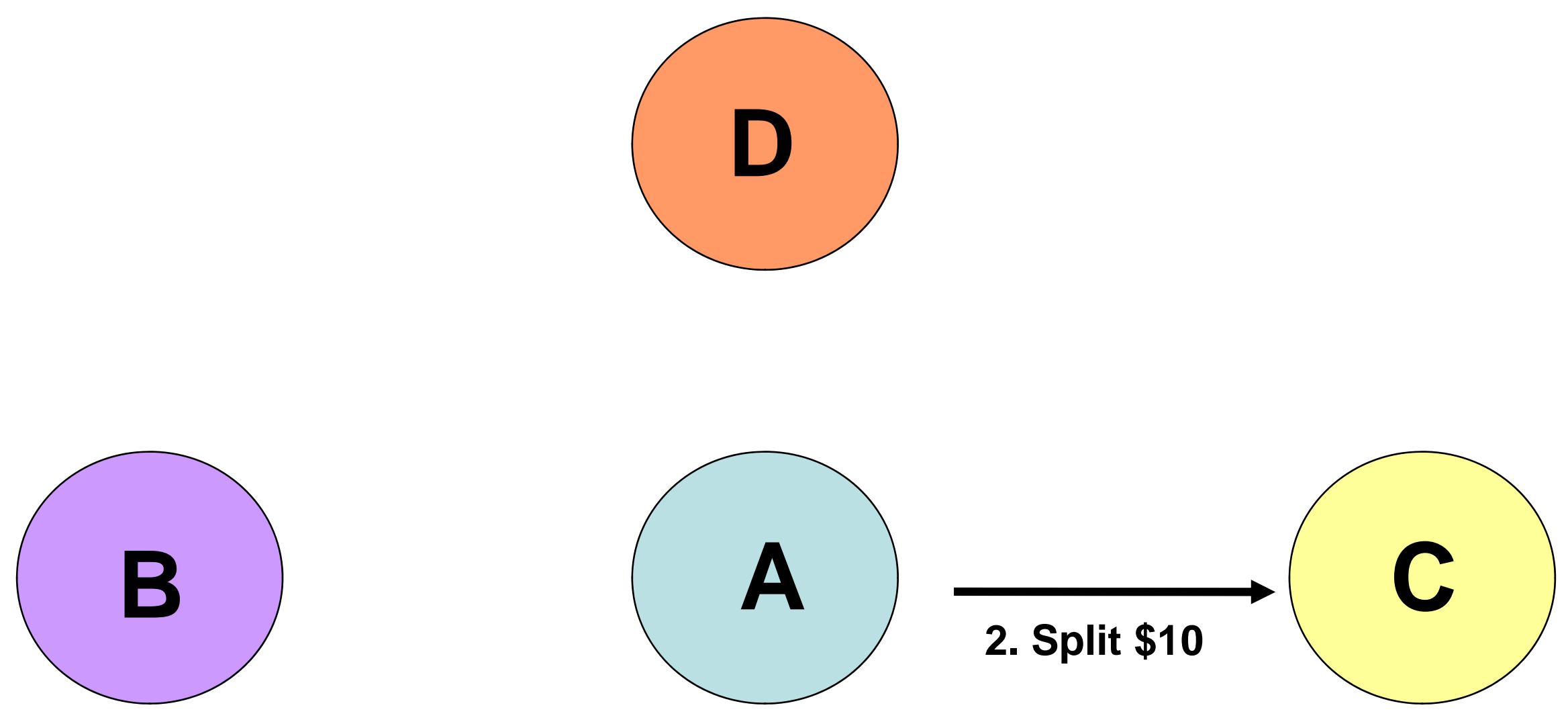
$C \$ 5$ for you, $\$ 5$ for Person $C$

C $\$ 6$ for you, $\$ 4$ for Person $C$

C $\$ 7$ for you, $\$ 3$ for Person $C$

C $\$ 8$ for you, $\$ 2$ for Person $C$

C $\$ 9$ for you, $\$ 1$ for Person $C$

C $\$ 10$ for you, $\$ 0$ for Person $C$ 


\section{"Sell"}
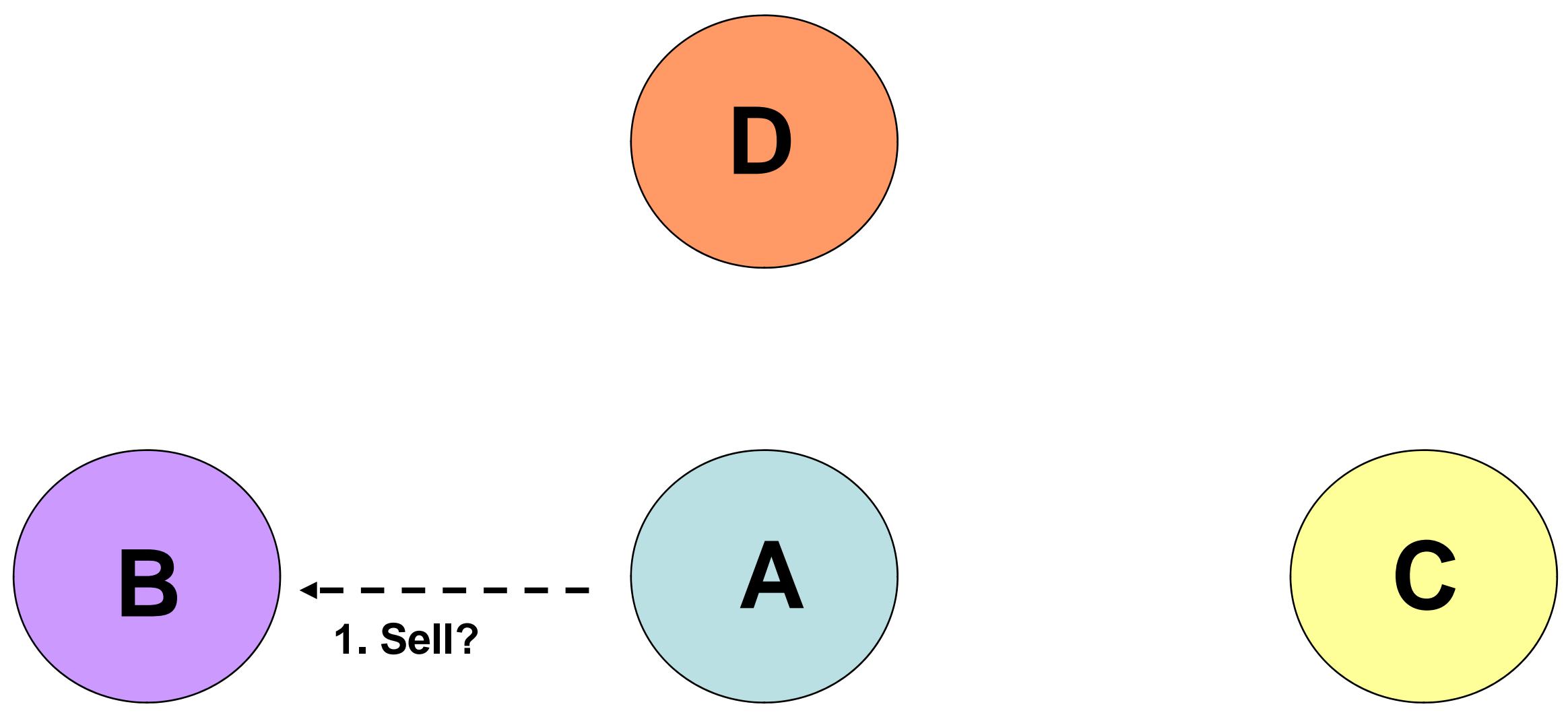
You own the rights to split $\mathbf{\$ 1 0}$ with Person $\mathrm{C}$. You will both be paid according to how you decide to split the $\$ 10$.

However, you can sell these rights now if you wish.

If you sell the rights, your profit will be the price you sell them for. If you do not sell them, your profit will be the amount of the $\$ 10$ you decide to keep.

Keep in mind, though, that Person D will be notified of all of your actions and will have the opportunity to reduce your profits.

Would you like to sell the "Split \$10" game?

No, Play the Split $\$ 10$ Game Myself

C Yes, Sell the Game to Player B 
You have chosen to sell the "Split $\$ 10$ " Game.

Choose how much you are selling it for:

$$
\begin{aligned}
& C \$ 10 \\
& C \$ 9 \\
& C \$ 8 \\
& C \$ 7 \\
& C \$ 6 \\
& C \$ 5
\end{aligned}
$$




\section{Punishment}

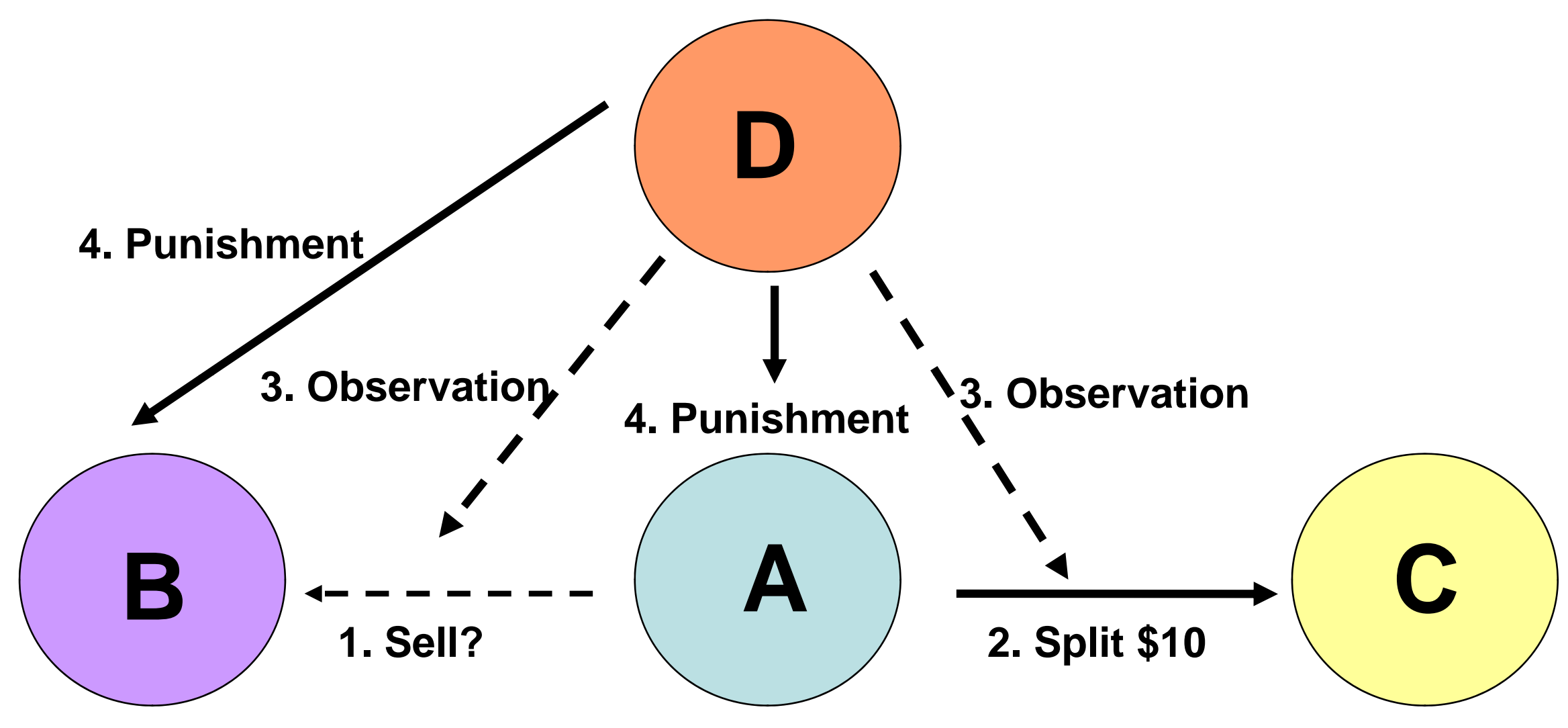


Suppose Person A sold the "Split \$10" game for $\$ 7$ to Person B.

And Person B kept \$8 and gave Person C \$2.

How much would you like to reduce PERSON A's payoff?

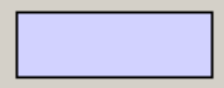

How much would you like to reduce PERSON B's payoff? 


\section{Questions?}

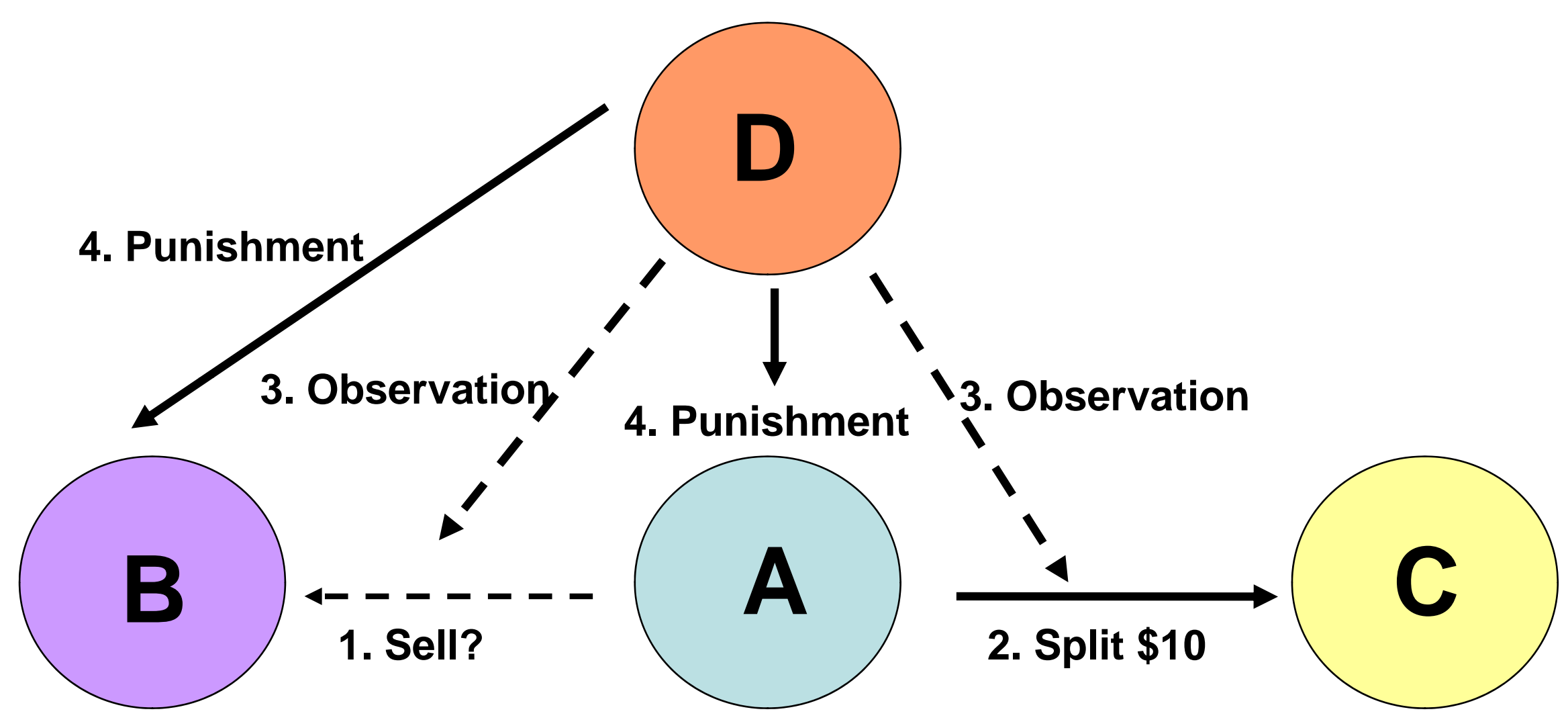




\section{Two Punishments - Script}

Below is the script that accompanied the slideshow that accompanied the instructions. As with the instructions, the script was read aloud by the experimenter to all subjects simultaneously.

Where the slides are used is noted in the included instructions in red.

$\underline{\text { Slide } 2}$

Let's see what the Split $\$ 10$ Game will look like when you actually play the game.

$\underline{\text { Slide } 3}$

If you play the Split $\$ 10$ Game, this is the screen you will see.

There are 6 ways you can split the $\$ 10$, and they are listed here.

$\$ 5$ for you, $\$ 5$ for person C. $\$ 6$ for you, $\$ 4$ for person C. $\$ 7$ for you, $\$ 3$ for person C.

$\$ 8$ for you, $\$ 2$ for person C. $\$ 9$ for you, $\$ 1$ for person C. $\$ 10$ for you, $\$ 0$ for person C. You highlight the radio button of the allocation you desire and hit "Done".

Person $C$ will not see this screen. They will only be told of your anonymous decision at the end of the experiment.

\section{$\underline{\text { Slide } 4}$}

Let's see what the sell decision will look like when you actually play the game.

\section{$\underline{\text { Slide } 5}$}

If you are player $\mathrm{A}$, this is the first screen you will see.

First, it recaps everything you already know from the instructions.

Then it asks if you would like to sell the Split $\$ 10$ Game.

If you select "No", you will play the Split $\$ 10$ Game as we just saw.

If you select "Yes", you will then see the pricing screen...

\section{$\underline{\text { Slide } 6}$}

... which looks like this.

You can sell the game for $\$ 5, \$ 6, \$ 7, \$ 8, \$ 9$ or $\$ 10$. Select the amount you want and hit "Sell".

Then, Player B plays the Split $\$ 10$ Game that we saw.

However, she must keep at least as much as she was forced to pay for the game. That is, if Player A sells her the Split $\$ 10$ Game for $\$ 8$ (Point to $\$ 8$ ), Player B must keep $\$ 8, \$ 9$, or $\$ 10$. Her profit is anything she keeps above $\$ 8$, and this is added to the $\$ 5$ she started with. 


\section{$\underline{\text { Slide } 7}$}

Let's see what the punishment decision will look like when you actually play the game. When you are Player D, we are going to ask for your punishment decision for every possible scenario in the game between A, B, and C. Whichever one actually happens, we will reduce Player A's and Player B's payout by the amount you decided for that scenario.

\section{$\underline{\text { Slide } 8}$}

Here's one example, just for illustration.

It says, "Suppose Person A sold the 'Split $\$ 10$ ' game for $\$ 7$ to Person B. And Person B kept $\$ 8$ and gave Person C $\$ 2$."

And then it asks how much you would like to reduce Person A's and Person B's payout. Enter the dollar amount by which you would like to reduce their payouts. You can reduce $\mathrm{A}$ and or $\mathrm{B}$ by any amount you want, all the way to $\$ 0$. So in this example, $A$ made $\$ 7$, and $B$ made $\$ 1$ profit, so you can enter any number between 0 and 7 in the first box to reduce A's payout and any number between 0 and 1 in the second box to reduce B's payout.

In this case, if the Person A in your group DID sell the game for $\$ 7$ and Person B subsequently kept $\$ 8$, then we would reduce A's and B's payouts by the numbers that you enter here.

There are 27 possible scenarios. We will ask you each, one at a time, in a random order.

\section{$\underline{\text { Slide } 9}$}

The last page is a summary broken down by role. Please review that and raise your hand if you have a question. We'll take a few minutes to answer all questions, and then we'll begin the game. 


\section{The Allow-Taking Game}

Experimental Instructions, accompanying slideshow and script. 


\section{Experiment Instructions}

\section{Preliminaries}

Thank you for participating in this study. If at any time you have questions, please raise your hand, and I will assist you. From now until the end of the session, communication of any kind between participants is not allowed. Please do not use the computer for any other purpose than participating in this study. Also, please turn off your cell phones.

\section{Overview}

The purpose of this session is to study decision making.

You will make a series of decisions that will affect your payoffs as well as the payoffs of others.

All studies run here in the Computer Lab for Experimental Research (CLER) do NOT use deception. Everything in these instructions is true, including the rules and the payoffs. Everyone received the same instructions.

What are my payoffs?

You will be paid your $\$ 10$ show up fee plus the money made during the course of the following game.

As an example just for illustrative purposes: If you make $\$ 5$ in the game, you will be paid \$15 total when you leave.

\section{The Game}

The game will be played in groups of four. We will play the game four times. Each time we play the game will be referred to as a "period".

In each period, everyone will be randomly assigned to one role and one group. You will play each role exactly once.

There are no computer players. The other three players in your group will be three other people in the room. You will be playing with three different people in each period.

Let's call the four roles A, B, C, and D. The game is completely anonymous, so players will only be referred to as A, B, C, or D for the duration of the experiment.

Here is how the game works:

Player A has $\$ 10$. He/she can give up to $\$ 5$

to Person B. Person B has $\$ 0$ otherwise.

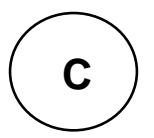

That is, A decides how to split the $\$ 10$, giving up to $\$ 5$ to $\mathrm{B}$, and the two players are paid accordingly. B has no say in the

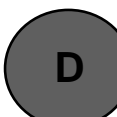

decision. B will simply be informed of A's anonymous decision.

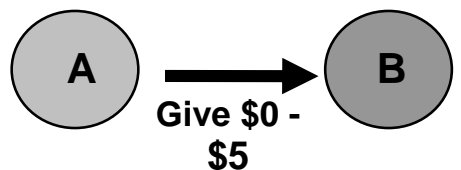

Show slides 2 and 3 with script. 
After $\mathrm{A}$ has given between $\$ 0$ and $\$ 5$ to player B, A makes one more decision.

A can allow Player $\mathrm{C}$ to take any amount of money from $\mathrm{B}$.

That is, $\mathrm{B}$ now has the money A gave to him/her, and if given the opportunity, C can
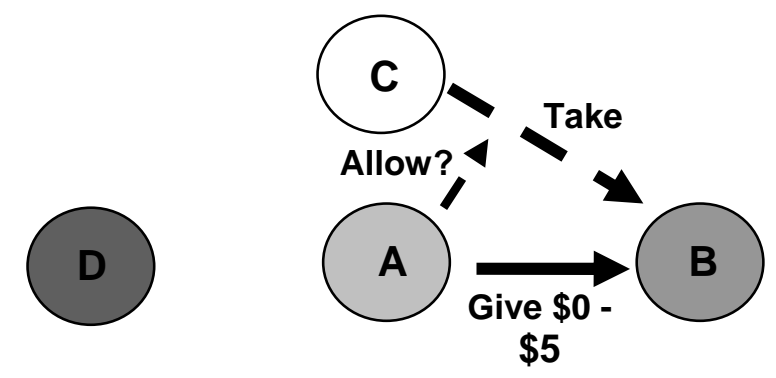
take any or all of it.

C has $\$ 5$ in addition to any money she takes from C..

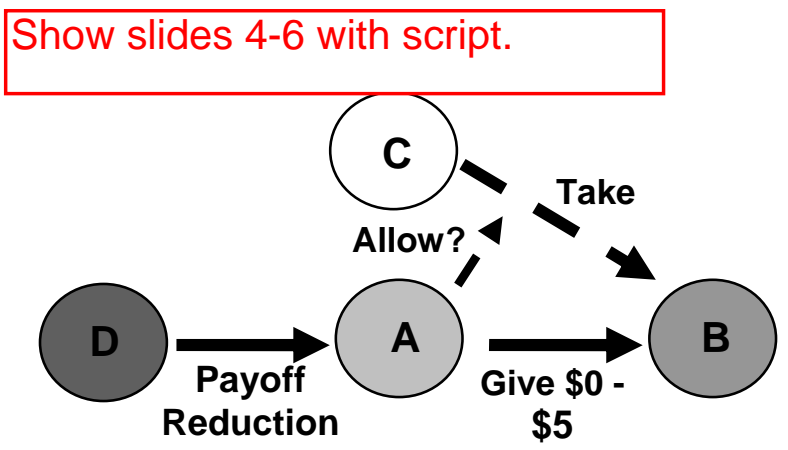

Player D then has the option of reducing Player A's payoff. They get to make this decision based on what happened in the game:

1. Whether $\mathrm{C}$ was allowed to take 2. If so, how much he/she took 3. How the $\$ 10$ was split with Player B

Player D can reduce Player A's payoff by any amount; However, she cannot reduce Player A to negative amounts.

So say Player A has $\$ 7$ (having gave $\$ 3$ to Player B). Player D can punish any amount between $\$ 0$ and $\$ 7$.

Player D earns exactly $\$ 5$ for the period no matter what punishment decisions she makes. Show slides 7 and 8 with script.

At the end of each period, you will not be told the decisions of the other players. We will learn what happened once we have played all four periods.

At that point, the computer will randomly choose one period. Your profits from that period, and that period only, will be the amount that you are paid when you leave, in addition to your show up fee.

Everyone will be paid for the same period. All four periods are equally likely to be the "payment period", so make thoughtful decisions in all four periods. 
Show slide 9 with script.

To recap, broken down by roles, the game is as follows:

Player A

- Owns the rights to anonymously split \$10 with B, without any input from B.

- Can give up to $\$ 5$ to $\mathrm{B}$.

- Can be punished by D

- Can decide whether or not to allow $\mathrm{C}$ to take money from B.

- Profit is equal to the amount A keeps of the $\$ 10$ minus the punishment decided by $\mathrm{D}$.

Player B

- Receives the amount that is sent by A minus any money that is taken by $\mathrm{C}$ if $\mathrm{A}$ allows $\mathrm{C}$ to take.

Player C

- Starts with $\$ 5$

- Cannot be punished by D

- If A so chooses, $\mathrm{C}$ can make additional money by taking from B.

- Profit equals \$5 plus any money taken from B.

Player D

- Based on the behavior of A and C, D can reduce A's payoff by any amount all the way to $\$ 0$.

- Profit equals \$5 no matter what.

\section{Are there any questions about how this game works?}

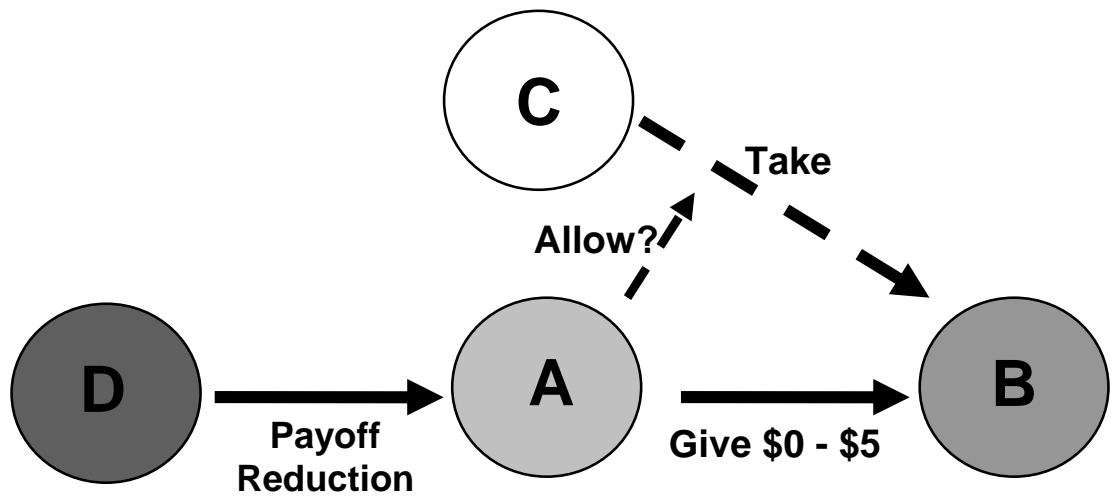

If at any time during the session you have questions, please raise your hand.

Good luck. 


\section{Welcome}

Please read and sign the consent forms.

We'll go through the instructions together. 


\section{The "Split \$10" Game}
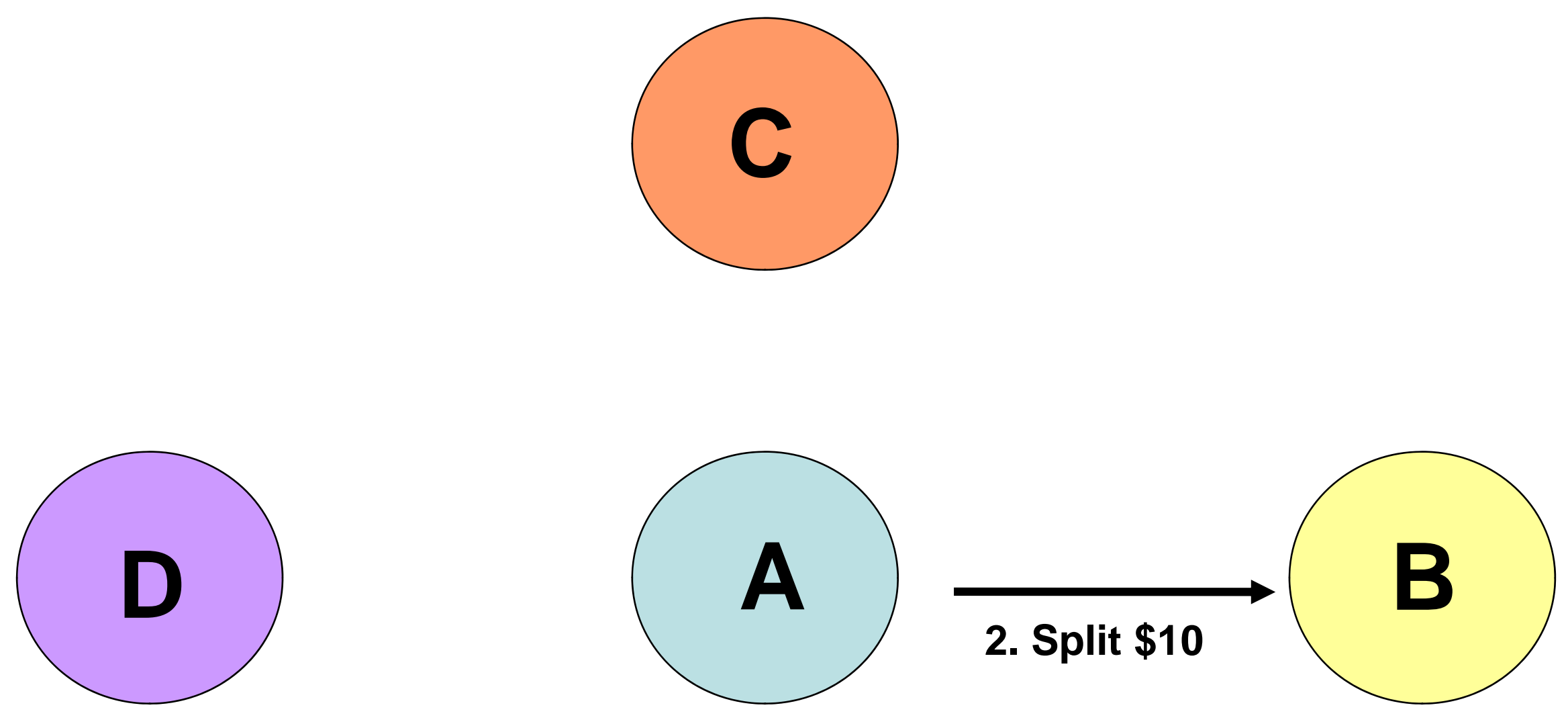
$C \$ 5$ for you, $\$ 5$ for Person $C$

C $\$ 6$ for you, $\$ 4$ for Person $C$

C $\$ 7$ for you, $\$ 3$ for Person $C$

C $\$ 8$ for you, $\$ 2$ for Person $C$

C $\$ 9$ for you, $\$ 1$ for Person $C$

C $\$ 10$ for you, $\$ 0$ for Person $C$ 


\section{Allow Taking?}
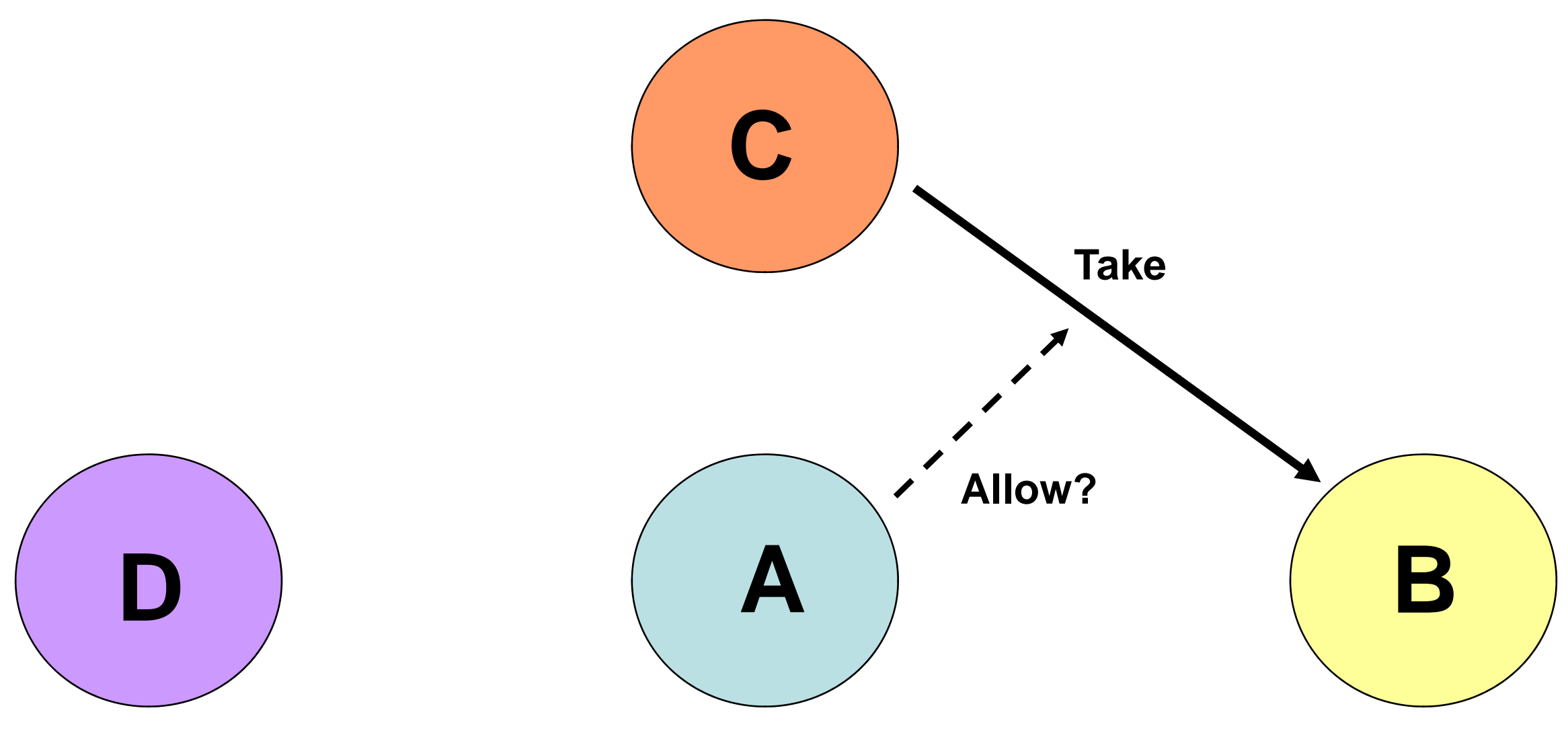
You chose to send C $\$ 3$.

You may allow Person $B$, who has $\$ 5$, to take as much as she chooses from this amount you sent.

Keep in mind that Person D will be notified of all of your actions and will have the opportunity to reduce your profits.

Would you like to allow Person B the option to take any amount she chooses from the money you sent $C$ ?

$$
\begin{aligned}
& C \text { No } \\
& C \text { Yes }
\end{aligned}
$$


A has elected to let you take from the $\$ 3$ he/she has cent $\mathrm{C}$.

Please decide how much you would like to take.

Recall that person $D$ will see what has happened and have the opportunity to decrease Person A's payoff. 


\section{Punishment}
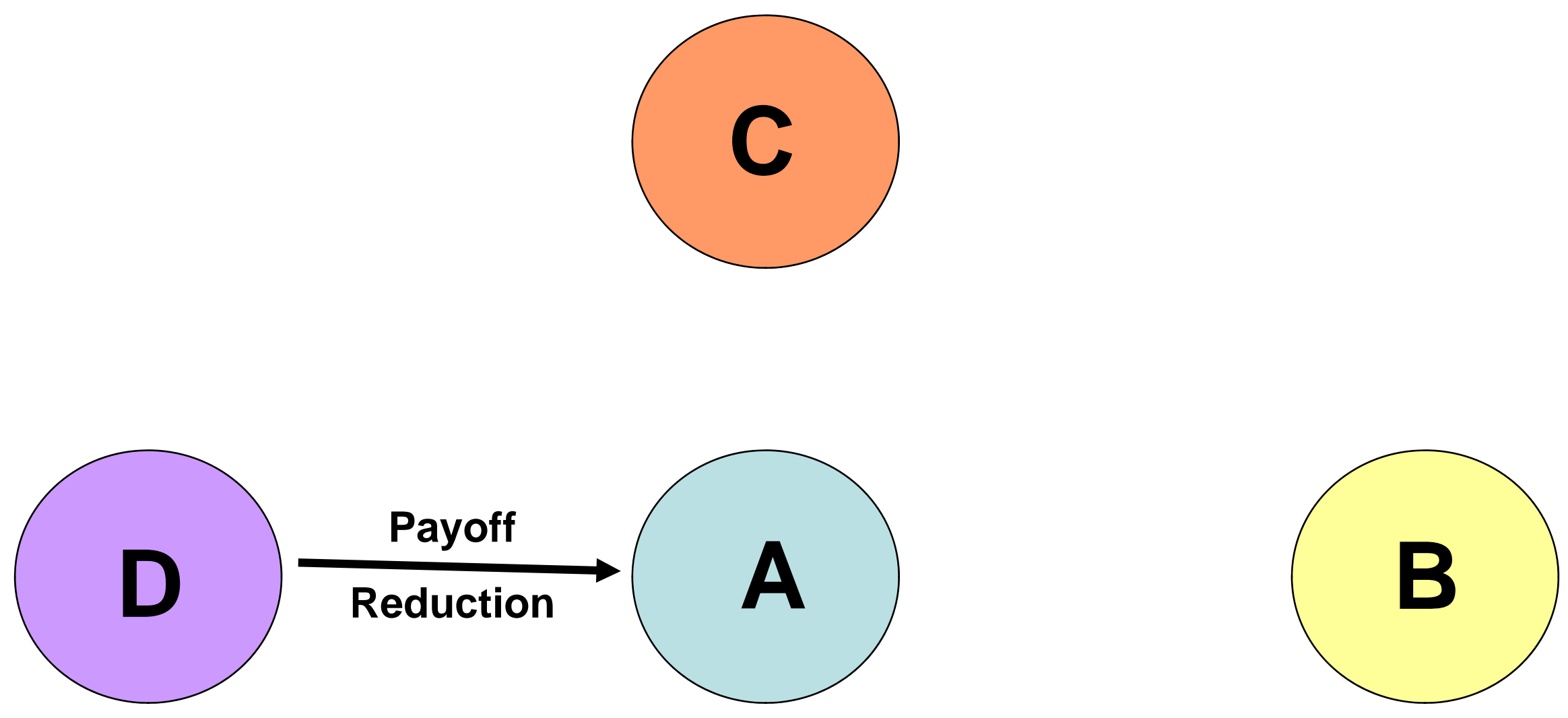
Suppose Person A gave Person C $\$ 3$ in the "Split $\$ 10 "$ game.

Subsequently, Person A decided to let Person B take from Person $C$.

And PERSON B took \$1.

How much would you like to reduce PERSON A's payoff? 


\section{Questions?}

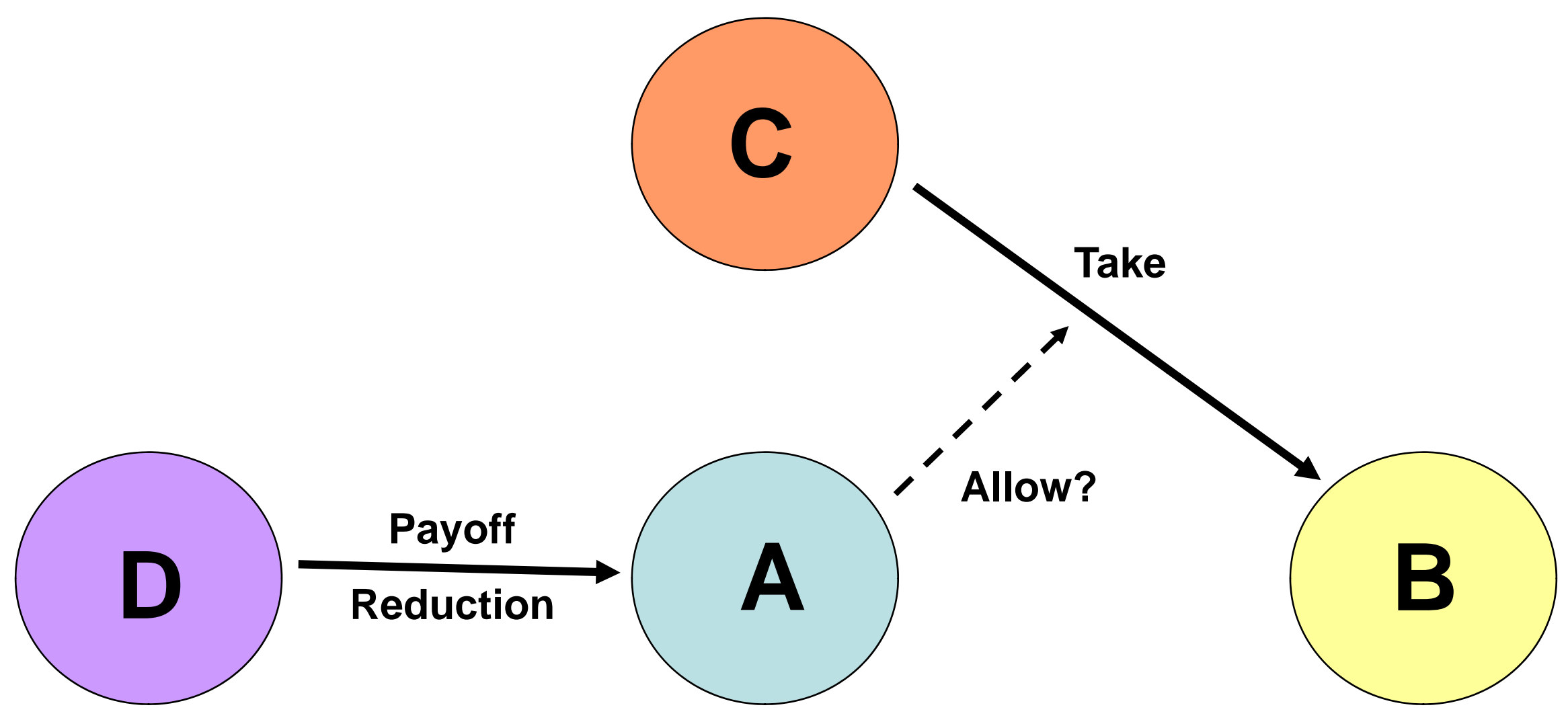




\section{Allow-Taking Game - Script}

Below is the script that accompanied the slideshow that accompanied the instructions. As with the instructions, the script was read aloud by the experimenter to all subjects simultaneously.

Where the slides are used is noted in the included instructions in red.

$\underline{\text { Slide } 2}$

Let's see what the Split $\$ 10$ Game will look like when you actually play the game.

$\underline{\text { Slide } 3}$

If you play the Split $\$ 10$ Game, this is the screen you will see.

There are 6 ways you can split the $\$ 10$, and they are listed here.

$\$ 5$ for you, $\$ 5$ for person C. $\$ 6$ for you, $\$ 4$ for person C. $\$ 7$ for you, $\$ 3$ for person C.

$\$ 8$ for you, $\$ 2$ for person C. $\$ 9$ for you, $\$ 1$ for person C. $\$ 10$ for you, $\$ 0$ for person C. You highlight the radio button of the allocation you desire and hit "Done".

Person $\mathrm{C}$ will not see this screen. They will only be told of your anonymous decision at the end of the experiment.

\section{$\underline{\text { Slide } 4}$}

Let's see what the allow-taking decision will look like when you actually play the game.

\section{$\underline{\text { Slide } 5}$}

If you are player $A$, this is the first screen you will see after you split $\$ 10$.

It reminds you how much you sent in the Split $\$ 10$ Game.

In this example, purely for illustration, Player A sent $\$ 3$.

Then it asks if you would like to allow Player B to take any amount she wants from Player C.

If you select "Yes", Player B will see the following screen...

\section{$\underline{\text { Slide } 6}$}

...which looks like this.

Recall in the example, which, again, is just for illustration, Player A sent $\$ 3$ to Player C.

Hence if Player B is allowed to take, she can take $\$ 0, \$ 1, \$ 2$, or $\$ 3$.

She makes this decision and then hits "OK".

This money is added to her $\$ 5$.

Whatever she does not take of the $\$ 3$ is Player C's payout. 


\section{$\underline{\text { Slide } 7}$}

Let's see what the punishment decision will look like when you actually play the game. When you are Player D, we are going to ask for your punishment decision for every possible scenario in the game between A, B, and C. Whichever one actually happens, we will reduce Player A's payout by the amount you decided for that scenario.

\section{$\underline{\text { Slide } 8}$}

Here's one example, just for illustration.

It says, "Suppose Person A gave Person C $\$ 3$ in the 'Split $\$ 10$ ' game. Subsequently, Person A decided to let Person B take from Person C.

And Person B took $\$ 1$ from Person C."

And then it asks how much you would like to reduce Person A's payout. Enter the dollar amount by which you would like to reduce A's payout.

You can reduce A by any amount you want, all the way to $\$ 0$. So in this example, A made $\$ 7$, so you can enter any number between 0 and 7 in the box.

And if the Person A in your group DID keep $\$ 7$ and Person B subsequently took $\$ 1$, then we would reduce A's payout by the number that you enter here.

There are 27 possible scenarios. We will ask you each, one at a time, in a random order.

\section{$\underline{\text { Slide } 9}$}

The last page is a summary broken down by role. Please review that and raise your hand if you have a question. We'll take a few minutes to answer all questions, and then we'll begin the game. 
The Forced-Taking Game

Experimental Instructions, accompanying slideshow and script. 


\section{Experiment Instructions}

\section{Preliminaries}

Thank you for participating in this study. If at any time you have questions, please raise your hand, and I will assist you. From now until the end of the session, communication of any kind between participants is not allowed. Please do not use the computer for any other purpose than participating in this study. Also, please turn off your cell phones.

\section{Overview}

The purpose of this session is to study decision making.

You will make a series of decisions that will affect your payoffs as well as the payoffs of others.

All studies run here in the Computer Lab for Experimental Research (CLER) do NOT use deception. Everything in these instructions is true, including the rules and the payoffs. Everyone received the same instructions.

What are my payoffs?

You will be paid your $\$ 10$ show up fee plus the money made during the course of the following game.

As an example just for illustrative purposes: If you make $\$ 5$ in the game, you will be paid $\$ 15$ total.

\section{The Game}

The game will be played in groups of four. We will play the game four times. Each time we play the game will be referred to as a "period".

In each period, everyone will be randomly assigned to one role and one group. You will play each role exactly once.

There are no computer players. The other three players in your group will be three other people in the room. You will be playing with three different people in each period.

Let's call the four roles A, B, C, and D. The game is completely anonymous, so players will only be referred to as A, B, C, or D for the duration of the experiment. 
Here is how the game works:

There is $\$ 10$ that can be split amongst $\mathrm{A}, \mathrm{B}$ and $\mathrm{C}$.

There are two possible processes by which the $\$ 10$ can be split.

Let's define them by how they begin:

Either A starts with the $\$ 10$, or C starts with the $\$ 10$.

Player A Starts with the $\$ 10$

If A starts with the $\$ 10$, she decides how to split the $\$ 10$ with $\mathrm{C}$ (and only $\mathrm{C}$ ) and the two players are paid accordingly. $\mathrm{C}$ has no say in the decision. $\mathrm{C}$ will simply be informed of A’s anonymous decision.

\section{Player C Starts with the $\$ 10$}

If $\mathrm{C}$ starts with the $\$ 10$, Player $\mathrm{B}$ will decide how much to take from her and distribute between herself and Player A.

First though, Player A will decide how much Player B will give to her.

Any amount Player B takes on top of the amount she will give to A is profit for Player B. She must take at least as much as she will give to Player A.

However much of the \$10 Player B does not take from Player C is Player C's profit.

A will choose who will start with the $\$ 10$.

Also, in either case, Player B automatically has \$5 in addition to any profit she earns in the game.

Show slides 2-7 with script.

Payoff Reduction

Player D then has the option of reducing Player A's payoff. They get to make this decision based on everything that happened in the game.

Player D can reduce Player A’s payoff by any amount;

However, she cannot reduce Player A to negative amounts.

So say Player A makes $\$ 7$ (either by keeping money or from having it passed by B).

Player D can punish any amount between $\$ 0$ and $\$ 7$.

Player D earns exactly \$5 for the period no matter what punishment decisions she makes.

Show slides 8 and 9 with script.

The Payment Period

At the end of each period, you will not be told the decisions of the other players. We will learn what happened once we have played all four periods.

At that point, the computer will randomly choose one period. Your profits from that period, and that period only, will be the amount that you are paid when you leave, in addition to your show up fee.

Everyone will be paid for the same period. All four periods are equally likely to be the "payment period", so make thoughtful decisions in all four periods. 
To recap, broken down by roles, the game is as follows:

Player A

- Decides the process by which $\$ 10$ will be distributed

- If she chooses to start with the $\$ 10$, she splits it with $C$, with no input from $C$. The amount she keeps is her winnings.

- If she chooses to have $C$ start with the $\$ 10$, A also chooses an amount that $\mathrm{B}$ will give to her. The amount she has $\mathrm{B}$ pass to her is her winnings.

- Can be punished by D

- Profit is equal to her winnings minus punishment decided by D.

Player B

- If C starts with the $\$ 10$, she decides how much to take. Her winnings are the amount she keeps minus the amount she gives to $\mathrm{A}$.

- Cannot be punished by D

- If B is not sold the Split $\$ 10$ game by A, winnings are 0 .

- Will be paid $\$ 5$ plus any winnings made in this game.

Player C

Player $D$

- Receives the amount that is decided by A or B. This is C's Profit.

- Based on the behavior of A and B, D can reduce A's payoff by any amount all the way to $\$ 0$.

- Profit equals \$5 no matter what.

If at any time during the session you have questions, please raise your hand.

Good luck. 


\section{Welcome}

Please read and sign the consent forms.

We'll go through the instructions together. 
Person A 
There are $\$ 10$ that will be split. There are two options for how this will happen.

Either you will start with $\$ 10$, and you will split it between yourself and Person C,

or Person C will start with $\$ \mathbf{1 0}$, and Person B will decide how much to take for you and herself.

If you decide to let Person $C$ start with $\$ 10$, you will also decide how much Person B must take from Person $C$ and pass to you. He/She will then decide how much to take of the $\$ 10$ given your decision. Everyone will be paid accordingly.

Keep in mind, though, that Person D will be notified of all of your actions and will have the opportunity to reduce your profits.

Would you like to start with the $\$ 10$ yourself or have Person $C$ start with the $\$ 10$ ?

\footnotetext{
C Start with the $\$ 10$ Myself
}

C Have Person C Start with $\$ 10$ 
You decided to split $\$ 10$ with Person C.

Please decide how to split $\$ 10$ between yourself and person $C$.

Whatever you decide is what will be paid out. Person $C$ has no say in the split.

Recall that person D will see what has happened and have the opportunity to decrease your payoff.

\footnotetext{
C $\$ 5$ for you, $\$ 5$ for Person $C$

C $\$ 6$ for you, $\$ 4$ for Person $C$

C $\$ 7$ for you, $\$ 3$ for Person $C$

C $\$ 8$ for you, $\$ 2$ for Person $\mathrm{C}$

C $\$ 9$ for you, $\$ 1$ for Person $C$

C $\$ 10$ for you, $\$ 0$ for Person $C$
} 
You have chosen to have Person C start with the $\$ 10$.

Choose how much Person B must take and pass to you:

$$
\begin{aligned}
& C \$ 10 \\
& C \$ 9 \\
& C \$ 8 \\
& C \$ 7 \\
& C \$ 6 \\
& C \$ 5
\end{aligned}
$$


Person B 
Person $\mathrm{C}$ has $\$ 10$. You must take at least $\$ 6$, which will be passed to Person A. Anything you take on top of that amount will be added to your profits.

Please decide how much of the $\$ 10$ to take from Person $C$.

Recall that person D will see what has happened and have the opportunity to decrease Person A's payoff.

$$
\begin{aligned}
& \text { C Take } \$ 5 \\
& \text { C Take } \$ 6 \\
& \text { C Take } \$ 7 \\
& \text { C Take } \$ 8 \\
& \text { C Take } \$ 9 \\
& \text { C Take } \$ 10
\end{aligned}
$$


Person D 
Suppose Person A decided to have Person C start with the $\$ 10$.

Person A also decided that Person B would give her $\$ 7$.

And Person B took \$8 from Person C, leaving him/her with $\$ 2$.

How much would you like to reduce PERSON A's payoff? 
Questions? 


\section{Forced-Taking Game - Script}

Below is the script that accompanied the slideshow that accompanied the instructions. As with the instructions, the script was read aloud by the experimenter to all subjects simultaneously.

Where the slides are used is noted in the included instructions in red.

$\underline{\text { Slide } 2}$

Here are the screens you will see when you are Player A.

$\underline{\text { Slide } 3}$

The first screen you will see will summarize the game; this is all the information we just went through.

It will then ask you whom you would like to start with the $\$ 10$ - yourself or Player C. You choose which one you would like, and click "OK".

\section{$\underline{\text { Slide } 4}$}

If you choose to start with the $\$ 10$ yourself, you will then play the Split $\$ 10$ Game, and this is the screen you will see.

There are 6 ways you can split the $\$ 10$, and they are listed here.

$\$ 5$ for you, $\$ 5$ for person C. $\$ 6$ for you, $\$ 4$ for person C. $\$ 7$ for you, $\$ 3$ for person C.

$\$ 8$ for you, $\$ 2$ for person C. $\$ 9$ for you, $\$ 1$ for person C. $\$ 10$ for you, $\$ 0$ for person C. You highlight the radio button of the allocation you desire and hit "Done".

Person $\mathrm{C}$ will not see this screen. They will only be told of your anonymous decision at the end of the experiment.

\section{$\underline{\text { Slide } 5}$}

If you choose to have Player $C$ start with the $\$ 10$, you will then decide how much Player B must take and pass to you.

This can be any amount from $\$ 5, \$ 6, \$ 7, \$ 8, \$ 9$, or $\$ 10$.

Make your decision, and click "OK".

$\underline{\text { Slide } 6}$

Here are the screens you might see when you are Player B.

\section{$\underline{\text { Slide } 7}$}

You will only make a decision if Player A decides to have Player C start with the $\$ 10$. If she does, you will be informed of this, as well as the amount that Player $\mathrm{A}$ has decided you must take from Player $\mathrm{C}$ and pass to Player $\mathrm{A}$. You must take at least this much, but you may take more. 
In this example, purely for illustration, Player A has decided you must take at least $\$ 6$. If you choose “ $\$ 5$ ”, you will get an error message.

In this example, any amount you choose over $\$ 6$ will be profit for you.

Player C's profit is any amount you choose not to take.

\section{$\underline{\text { Slide } 8}$}

And here are the screens you will see when you are Player D.

When you are Player D, we are going to ask for your punishment decision for every possible scenario in the game between A, B, and C. Whichever one actually happens, we will reduce Player A's payout by the amount you decided for that scenario.

\section{$\underline{\text { Slide } 9}$}

Here's one example, just for illustration.

It says, "Suppose Person A decided to have Person C start with the $\$ 10$. Person A also decided that Person B would give her $\$ 7$. And Person B took $\$ 8$ from Person $C$, leaving him/her with $\$ 2$."

And then it asks how much you would like to reduce Person A's payout. Enter the dollar amount by which you would like to reduce A's payout.

You can reduce A by any amount you want, all the way to $\$ 0$. So in this example, A made $\$ 7$, so you can enter any number between 0 and 7 in the box.

And if the Person A in your group DID choose to have C start with the $\$ 10$ and DID choose to have $\mathrm{B}$ take and pass to her $\$ 7$ and Person $\mathrm{B}$ subsequently took $\$ 8$, then we would reduce A's payout by the number that you enter here.

There are 27 possible scenarios. We will ask you each, one at a time, in a random order.

$\underline{\text { Slide } 10}$

The last page is a summary broken down by role. Please review that and raise your hand if you have a question. We'll take a few minutes to answer all questions, and then we'll begin the game. 